\title{
PROCEEDINGS OF THE TWENTY-EIGHTH ANNUAL MEETING OF THE AMERICAN SOCIETY FOR CLINICAL INVESTIGATION HELD IN ATLANTIC CITY, N. J., MAY 4, 1936
}

\author{
READ BEFORE JOINT SESSION
}

Streptococcus Immune Bodies in Rheumatic Fever and in Comparable Control Groups. By JoHn R. Mote (by invitation) and T. Ducketr Jones, Boston, Mass.

The results of the antibody response to streptolysin, fibrinolysin, and precipitins to the $C$, carbohydrate fraction, and the $D, E, K$, and $P$ fractions of the hemolytic streptococci were studied in 90 cases of scarlet fever, in 56 cases of pharyngitis in non-rheumatic subjects, in 262 rheumatic recurrences, and in 218 upper respiratory infections in rheumatic subjects without recurrences.

It was found that over 90 per cent of the cases with scarlet fever and pharyngitis had an immune response to one or more of the antigens used.

Of the patients with rheumatic recurrences 40 per cent had no preceding respiratory infection, and 33 per cent had no antibody response to any antigen studied.

Of the 218 respiratory infections which are commonly followed by rheumatic fever in rheumatic subjects, 36.4 per cent had no antibody response to any of the antigens used. The great similarity of the percentage of cases having an antibody response whether a recurrence developed or not, is striking. However, the antibody response in the group without recurrences was in general not so great as in the group with recurrences.

In view of these findings it is concluded that although respiratory infections, especially those associated with the hemolytic streptococcus, are common precursors to rheumatic fever recurrences there must be some other factor than the streptococcus to account for the facts as found.

Bacterial Endocarditis Following the Ingestion of Bacteria. By R. O. Muether (by invitation) and $R$. A. Kinsella, St. Louis, Mo.

In a previous communication a method for the producduction of experimental bacterial endocarditis was discussed. Since that time we have had the opportunity of seeing endocarditis with septicemia develop in a number of animals which were fed a mixture of dog "chow" and living bacteria, following the mechanical damage of a valve of the heart.

Methods. Twelve healthy dogs, varying in size from six to twelve kilograms were operated under intravenous barbital anesthesia in the manner previously described. Upon regaining consciousness, a mixture of "chow" and Streptococcus viridans (10 cc. 24 hour broth culture), was offered and this food was taken daily until a positive blood culture was obtained, or until seven to twenty-one days had elapsed. Following this procedure five animals developed septicemia and died, showing at autopsy the pathological picture of septicemia and bacterial endocarditis. The gastro-intestinal tract showed no macroscopic lesions.

An attempt to determine whether or not the organisms recovered from the infected dogs were identical with those which had been fed was made. Sugar reactions and agglutination tests were done for this purpose.

The bacteria whicb we used were obtained from a case of subacute bacterial endocarditis. These bacteria, as well as those recovered, were planted in mannite, lactase, sucrose, raffinose, inulin, and salicin.

The agglutination tests were done with rabbit's serum obtained from rabbits injected subcutaneously, and intravenously with living bacteria obtained from the original human source. Injections were begun with one-half cc. given subcutaneously, and were increased a half cc., every other day until $3 \mathrm{cc}$. had been given. One-half cc. was then injected intravenously and increased by onehalf cc. every other day until five cc. were given. Ten days were allowed to elapse after the last injection, and preliminary titration showed that the serum agglutinated the original organisms in a dilution of $1 / 1280$. The bacteria recovered from the animals were then tested.

Results. The five dogs which did not yield a positive blood culture after feeding were finally injected intravenously with Streptococcus viridans as indicated in the table. All then gave positive blood cultures. One died three days after the positive blood culture was obtained, and the others are under treatment.

Three dogs which made up a total of twelve died within twenty-four hours of their first feeding and were discarded.

The sugar reactions were remarkably constant. Only one discrepancy was found. These bacteria failed to ferment mannite at first, but subsequent tests gave uniform results. Two cultures of bacteria obtained from the patient also yielded consistent results.

The agglutination tests were also consistent. Strong agglutination was obtained in all dilutions up to and including $1: 1280$. The bacteria used in this experiment grew smooth, and thus facilitated the use of agglutination tests.

Conclusions. On the basis of information available, it would seem that a septicemia may develop following feeding of a mixture of dog "chow" and living bacteria to dogs whose heart valves have been recently damaged. When these bacteria lodge upon the damaged heart valve they produce vegetations which resemble bacterial endocarditis produced by intravenous injection. Endocarditis and septicemia so produced is rapidly fatal.

Experimentally Induced Nephritis in Rats. Functional and Clinical Studies. By LEE E. FARR and JOSEPH E. Smadel (introduced by Homer F. Swift), New York, N. Y.

Sera obtained by immunizing rabbits with emulsion of perfused rat kidney induced in rats a nephritis charac- 
terized histologically by progressive glomerular and tubular destruction. Twenty-four rats were observed for preliminary periods of three weeks to one month while blood and urine chemical studies, and urea clearances, were done. These rats were then injected with varying amounts of anti-kidney serum, and followed for periods up to 313 days. The animals uniformly developed nephritis. Some died in the acute stage; others were killed at intervals to supplement histological data obtained from those dying spontaneously. Of those surviving the acute stage, the majority developed a progressive chronic nephritis; a few recovered, some completely. Albuminuria, casts, plasma protein deficit, lipemia and slight to marked depression of urea clearance, without hypertension or retinal changes, characterized the acute nephritis; and during this phase, animals became markedly edematous, with ascites, hydrothorax and generalized subcutaneous edema. Animals with chronic lesions and in terminal phases of the disease showed marked reduction in urea clearance with blood urea nitrogen up to $350 \mathrm{mgm}$. per cent, anemia, hypertension, moderate plasma protein deficit, malnutrition, transient edema, cessation of growth and slight retinopathy. In many respects this induced disease simulated Bright's disease in man.

The Effect on the Kidneys of Bilateral Splanchnicectomy in Patients with Hypertensive Vascular Disease. By R. H. Freyberg and M. M. PeEt (introduced by F. N. Wilson), Ann Arbor, Mich.

The concentrating ability of the kidneys, urea clearance, proteinuria, and formed elements of the urine sediment were measured in patients with hypertensive vascular disease ("essential" or "malignant" hypertension) before and at varying lengths of time after resection of both greater and lesser splanchnic nerves. In thirty-two patients with adequate postoperative study the results were in general as follows. In those patients (53 per cent) who had a significant and maintained decrease in blood pressure following splanchnicectomy, the urinary abnormalities decreased or disappeared and the renal function, if it had been impaired, improved-in several cases it became entirely normal. When hypertension was lowered in patients having normal renal function prior to operation the kidney efficiency remained normal. When hypertension was not favorably influenced by this operation, renal function remained unchanged or became gradually worse, although proteinuria was frequently less.

The results of these studies show that the hypertension is not compensatory to measurable renal damage; that marked impairment of renal function may accompany hypertensive vascular disease; and that striking improvement of function follows relief of the hypertension.

The Action of Protamine Insulin in Normal and Depancreatized Dogs. By ROBERT B. KERR (introduced by C. H. Best), Toronto, Canada.

The action of protamine insulin, which was first described by Hagedorn, Jensen, Krarup and Wodstrup, has been studied in normal and depancreatized dogs. The protamine was prepared from the sperm of the "Spring Salmon" (Onchorhynchus tschawytscha) by Scott and Fisher of the Connaught Laboratories.

The prolongation of the action of insulin by the addition of protamine has been demonstrated in normal dogs. The blood sugar has been lowered for 12 to 30 hours following large doses of protamine insulin without hyperglycemic convulsions.

It is possible to keep depancreatized dogs in good condition and "sugar free" on a liberal diet of two feedings per day with one dose of protamine insulin daily. Glycosuria is much increased when one dose of regular insulin, of the same number of units, is substituted for protamine insulin. The blood sugar of depancreatized dogs remains at a much more uniform level throughout the 24 hours when the animal is receiving protamine insulin than when regular insulin is being given.

The addition of zinc salts to isulin has been found to prolong its action in dogs in confirmation of the work of Scott and Fisher in rabbits. In further confirmation of the work of these authors, ash free preparations of insulin and protamine show considerably shorter duration of action than do the same preparations to which a small amount of a zinc salt has been added.

The possibility of toxic effects resulting from the administration of protamine has been studied.

The Effect on the Human Electroencephalogram of Various Drugs Which Influence Nervous Activity. By F. A. Gibss and E. L. GibBs (by invitation) and W. G. Lennox, Boston, Mass.

The fluctuations in electrical potential which can be lead off the head are modified by certain drugs in therapeutic doses. The most definite changes attend the use of convulsants, sedatives and anesthetics. Drugs primarily affecting the autonomic nervous system produce little change.

Sedatives cause changes similar to those observed in normal sleep. In place of the fast rather steady activity characteristic of the waking state, there are slow large voltage fluctuations with occasional bursts of fast activity and also short periods in which there are almost no fluctuations. If sedation is so heavy that the patient cannot be aroused, the bursts of fast activity disappear, the slow components become slower and of larger voltage, and almost continuous. Ether produces first a decreased voltage and increased frequency and later large voltage waves without fast components. Electroencephalography may, therefore, be of value in controlling depth of anesthesia and sedation.

Convulsants produce large voltage disturbances such as are seen in epilepsy; the frequency may be fast or slow. In patients having frequent petit mal seizures, bromide or phenobarbital in doses insufficient to change normal electrical activity prevents or disorganizes the pattern of the discharge which characterizes the seizure. 
Familial Lipemia of Undetermined Origin. By L. EMMETT HolT, JR., and (by invitation) FrancIS X. AYLWARD and HARRY G. TIMBUS, Baltimore, Md.

An eleven year old girl was observed who from the age of four years had suffered from periodic acute attacks with abdominal pain and rigidity, vomiting, fever and collapse-the attacks lasting one to four days and subsiding spontaneously. On one of these occasions the abdomen had been explored without finding an explanation for the symptoms. There was also a history of psoriasis, worse in the summer time, and of chronic ulcers on the legs appearing in the summer following minor trauma, resisting all treatment but healing spontaneously in the winter. On examination the patient was somewhat undernourished; in addition to some characteristic lesions of psoriasis she showed two chronic granulating ulcers on the leg; the liver and spleen were enlarged, the former being four fingerbreadths and the latter two fingerbreadths below the costal margin. The eye grounds showed typical lipemia retinalis; the blood serum was milky and contained more than seven per cent fat, the excess consisting almost entirely of neutral fat.

A careful study failed to reveal any evidence for any of the familiar causes of lipemia: the carbohydrate metabolism was normal; renal function and liver functionthe latter studied by carbohydrate and dye tests-were normal; there was no evidence of poisoning, of anemia or of endocrinopathy. Studies of the respiratory metabolism revealed no difficulty in burning fat. It was not possible to determine whether the lipemia resulted from difficulty in removing fat from the blood or from excessive mobilization of depot fat.

While the patient was under observation a number of typical abdominal attacks occurred; at the termination of each one it was found that the lipemia had disappeared, the blood fat being only slightly above the normal value. It would then gradually increase toward a critical level of about eight per cent when another attack would occur and the process would be repeated. Attempts were made to reduce the blood fat by means of choline, insulin, liver extract, thyroxin, anterior pituitary extract and by transfusions with little success. Despite these measures the blood fat would rise; the rise was, however, somewhat less rapid on the choline period. When the fat intake was reduced to fifteen grams a day and five grams a day of choline given by mouth in addition, the blood fat gradually fell and the lipemia disappeared. The liver and spleen decreased markedly in size, the patient's general appearance was improved, and she began to gain weight. It is questionable whether this improvement is being maintained on the low fat diet without choline.

An investigation of the patient's family revealed that a younger brother of two and a half years had an enlarged liver and spleen, lipemia of the retina and a blood fat of three per cent. He had not had attacks similar to those in the patient.

It is suggested that we are dealing here with a familial anomaly of lipid metabolism, analogous to Gaucher's disease, Niemann-Pick disease and xanthomatosis, with the exception that in this condition it is neutral fat rather than other lipids which are not normally disposed of and which therefore tend to accumulate in the phagocytic cells of the reticulo-endothelial system, causing hypertrophy of the liver and spleen.

Observations on the Gastric Secretion of Man. By Leon Schiff, Cincinnati, Ohio.

During the past four and one half years over six hundred fractional gastric analyses have been made on one individual under similar conditions, both with and without histamine. On two occasions, each lasting many weeks, the patient developed post-histamine achlorhydria. Analyses of the gastric juice made during the phases of achlorhydria are compared with those made during phases of normal secretion. These include determinations of volume, acidity, chloride, base, pepsin and the "intrinsic" anti-anemic factor.

It is hoped that these observations may throw some light on the mechanism of the secretion of gastric juice.

The Manner of Removal of Aqueous Solutions from Joints. By Granville A. Bennett, Frederic W. RHINelander, 2ND. (by invitation), and Walter BAuER, Boston, Mass.

Previous studies have shown that proteins are removed from normal joints only by way of the lymphatics. Similar information concerning the removal of simple aqueous solutions is necessary in order better to interpret the manner of fluid exchange in normal and pathological joints.

The manner of absorption of aqueous solutions from cat knee joints was determined by recording the blood pressure changes following the intra-articular injection of vasoconstrictor and vasodilator solutions. The total amount absorbed was calculated by assaying the joint washings at the end of each experiment.

Adrenalin apparently produced sufficient local vasoconstriction to prevent its absorption in detectable amounts. The prompt systemic effects following injection of pituitrin and pilocarpine indicated rapid absorption via the capillaries.

Acetyl choline (" mecholyl" acetyl-beta-methylocholine chloride, Merck) was employed in most experiments. Its absorption from normal joints was demonstrable within 30 seconds. This early effect and its inhibition by intraarticular injection of adrenalin likewise indicated absorption via the capillaries.

Exercise increased absorption under all conditions. Previous removal of synovial fluid or slight inflammation did not significantly affect absorption. Absorption was strikingly increased from acutely inflamed joints.

In two of nine experiments done on eserinized cats, acetyl choline was demonstrable in thoracic duct lymph samples at the end of 45 and 60 minutes.

Thus it would appear that the chief route of absorption from a joint of an aqueous solution such as acetyl choline is by way of the subsynovial capillaries. 
Studies on the Relief of Pain by Counterirritation. By George D. Gammon (by invitation) and IsaAc StarR, JR., Philadelphia, $\mathrm{Pa}$.

The authors induced pain in themselves by skin irritants and by the subcutaneous injection of hypertonic $\mathrm{NaCl}$, applied heat, cold, electrical and mechanical counterirritation, and studied the relief afforded. The effectiveness of certain agents varied greatly in the two types of pain, e.g. heat relieved pain after $\mathrm{NaCl}$ injection but increased that from irritants.

The application of any counterirritant was usually followed by relief of short duration; when pain returned the removal of the counterirritant was also followed by relief. In certain instances rhythmic application and removal of the counterirritation relieved severe pain which constant application could not control.

Experimentally induced pain and its relief have been further analyzed in man by observing the changes caused by experimental alteration of the circulation and, with the aid of Dr. D. W. Bronk, in anesthetized cats by records of action potentials in cutaneous nerves. Skin injury evokes a discharge of rapid impulses which is greatly increased by heat and which shows little decline due to adaptation.

The studies made on induced pain have been repeated on 40 patients with pain of various origin. Visceral, cutaneous, and neuritic pain respond differently to different counterirritants, a fact which suggests a means of differential diagnosis.

\section{READ BEFORE SECTION A}

The Circulation in Lobar Pneumonia with Special Reference to Pulmonary Edema. By W. M. Hitzig, F. H. King, J. G. M. Bullowa (by invitation), and Arthur M. Fishberg, New York, N. Y.

Seventy-five patients were studied at the height of lobar pneumonia. Arm-to-tongue circulation time (saccharin) was normal in 67 , prolonged in 8 . Of these 8 , 4 had preëxistent heart disease. Arm-to-lung time (ether) paralleled arm-to-tongue time. Normal circulation time was observed within 30 minutes of death. Venous pressure was normal in 66, elevated in 9. Of those with elevated venous pressure, 3 had preëxistent heart disease, in 2 it was secondary to alterations in respiratory mechanics due to pulmonary edema, and 1 had singultous. Circulating blood volume (congo red, 65 cases) was normal. Eight patients were studied at the height of pulmonary edema ( 7 fatalities). All had normal circulation time. Six had normal venous pressure, 2 slight elevation.

Conclusions. Heart failure sufficient to retard blood flow is very rare in pneumonia without preëxistent cardiac disease. This supports the view that routine digitalization is inadvisable.

The normal circulation time indicates that pulmonary edema in pneumonia is not due to heart failure. Previous investigators have found evidence of pulmonary hypertension and generalized increase in capillary per- meability in pneumonia. It is suggested that these factors participate in the pathogenesis of pulmonary edema in pneumonia.

Vasomotor Collapse. By Soma WeIss and (by invitation) Robert W. Wilkins, Boston, Mass.

Sodium nitrite in small amounts which induce no appreciable changes in the hemodynamics in the horizontal position of the body disturbs the cardiovascular adjustment essential for the upright position. As a result, progressive manifestations of circulatory collapse develop within 20 to 60 minutes, accompanied by symptoms and signs of collapse identical with those observed in disease. During the first and symptom-free stage the small pulse pressure, rapid heart rate and thready pulse of 140 to 150 per minute are associated with increased arterial and venous tone, but with unchanged height of the effective venous column of the blood and with unaltered arteriovenous oxygen difference and blood flow. Later, when pallor, ashy-gray color of the skin, "coldbeaded" perspiration, lassitude and drowsiness appear, the pulse pressure is but 6 to $10 \mathrm{~mm}$. $\mathrm{Hg}$, and as a result of the failing adjustments, the effective venous column and blood flow fall, and the oxygen difference increases. During this stage yawning, sighing and deep respiration represent adjusting functions, which may temporarily bring the blood flow back to normal. Finally a stage is reached when the markedly decreased blood flow, which may be 25 per cent of the normal level in the hand and presumably in the brain, accentuates the parasympathetic manifestations, and complete circulatory collapse and unconsciousness develop. Following the return of the body to horizontal position the symptoms promptly disappear, and the circulation becomes normal within 1 or 2 minutes. Comparative observations indicate that the circulatory changes in syncope, collapse and shock are similar, the most obvious difference being the time element.

Evaluation of Medicinal Treatment in Angina Pectoris. By Joseph E. F. Riseman and Morton G. Brown (introduced by Herrman L. Blumgart), Boston, Mass.

The efficacy of medicinal therapy in angina pectoris was evaluated in thirty patients by observing changes in the clinical frequency of attacks and by quantitating the amount of effort possible under standardized conditions before inducing an attack.

Evaluation by clinical means indicated that improvement followed placebo pills as frequently as any other form of medication. The standardized exercise tolerance test revealed no significant improvement following placebo pills, sodium bicarbonate, potassium iodide, or oral tissue extract. About one-third of the patients failed to benefit by any of the fifteen different drugs employed.

Nitroglycerine given prophylactically enabled about two-thirds of the patients to undertake approximately 100 per cent more exercise before inducing angina; in many patients this prophylactic effect was evident for as long as one hour. About one-half of the patients were 
improved by aminophyllin or quinidine sulphate; one-third by erythrol tetranitrate, codeine sulphate or atropine sulphate; and one-fifth by sodium nitrite, theophyllin calcium salicylate or dinitrophenol. Phenobarbital was rarely of benefit. Digitalis frequently caused a marked increase in pain and reduction in the amount of exercise possible.

The duration of action and the optimal dosage were also determined. In several individuals nitroglycerine, grains $1 / 500$, taken every hour rendered the patients free of attacks in daily life. Complete disappearance of cardiac pain following medication was rare. Aminophyllin and nitroglycerine caused an increase in exercise tolerance of about 20 per cent to 100 per cent.

The Capillary Supply of the Rabbit Heart in Experimental Hypertrophy. By R. A. ShIPLEY and Louise J. ZschIesche (by invitation), and J. T. Wearn, Cleveland, Ohio.

If, in cardiac hypertrophy, there should be an increase in the mass of muscle tissue without a corresponding increase in the number of accompanying capillaries, a point might be reached when the tissue would suffer from a deficiency in the exchange of metabolic substances.

A quantitation has been made of the number of capillaries per unit of tissue in hearts with hypertrophy produced experimentally in rabbits. Hypertrophy resulted in an increase in the diameter of the muscle fibers with a consequent decrease in the concentration of capillaries in the cross sectional plane. During normal growth it was found that enlargement of fibers was accompanied by a birth of capillaries so that the concentration of capillaries per unit of tissue remained constant.

\section{The Coronary Flow in Dilated Human Hearts. By WIL-} Liam B. Kountz, St. Louis, Mo.

The work of Anrep has established that in a state of contraction the coronary flow of a dog's heart is considerably reduced. Because of the thinness of the muscle walls and the irritability of the dog's heart it is impossible to study the effect of dilatation on the coronary flow. The heart of man, however, has a relatively large muscle mass which enables it to maintain an adequate blood pressure even though the diastolic volume is greatly increased. For this reason we have attempted to establish the effect of dilatation of the human heart on the coronary flow.

Hearts were revived and made into a heart-lung preparation. The coronary flow was measured by placing cannulae in the coronary arteries and perfusing from a reservoir, in the top of which was inserted an instrument for measuring the amount of air displaced by blood flowing into the arteries. The volume of the heart was measured by an oncometer placed over the heart after the heart-lung preparation had been completed.

After a record of the coronary flow and the heart volume had been taken the organ was caused to dilate by stopping the coronary flow and producing asphyxia. The heart could be seen to dilate, and when its volume increased to the point where it could just sustain a systolic blood pressure of $120 \mathrm{~mm}$. of mercury, the coronary system was opened and the flow and heart volume were measured.

The effect of drugs upon the coronary flow and cardiac volume was then determined by injection into the perfusing system. Three groups of drugs were used in this study. The first consisted of three different digitalis preparations, which were chosen because it has been shown that they decrease the diastolic volume of the normal heart and also decrease the coronary artery flow. The second group of drugs were known coronary dilators of which histamine and sodium nitrite were the chief ones used. These drugs are also known to increase the diastolic volume of the normal heart. The third group consisted of the xanthine compounds, of which theobromine was chiefly used. This drug dilates the coronary arteries but does not change the cardiac volume.

When the compounds of digitalis were injected into the coronary arteries of the dilated heart there was a rather marked decrease of the diastolic volume of the heart and an increase in the flow into the coronary arteries. Theobromine had very little effect on the coronary flow. On the other hand, histamine, which increased coronary flow in the normal heart, definitely decreased it in dilated hearts.

These experiments, we believe, tend to emphasize two points, one physiological and the other clinical. From a physiological standpoint they serve to emphasize that changes in the heart from its normal diastolic state, whether by dilatation or contraction, produce a decrease in the coronary flow. Anrep has explained the decreased flow in the contracted heart by assuming that there is a squeezing and narrowing of the capillary bed. We suggest that the decreased flow with dilatation is due to a linear traction on the blood vessels of the heart which produces a narrowing of the capillaries and consequent decrease in the vascular bed.

From a clinical standpoint, not only the state of the coronary vessels but also the degree of contraction or dilatation of the cardiac chambers must be considered. No single coronary dilator can be expected to exert a favorable action in all cases.

Concerning a New Concept of the Genesis of the Electrocardiogram. By L. N. KATZ and (by invitation) A. Bohning, M. Robinow, I. Guttman, H. Korey and F. Ocko, Chicago, Ill.

Studies carried out in this laboratory during the past few years have lead us to a new concept of the genesis of the electrocardiogram. The problem concerns the electrical field created by the heart. This can be divided into three phases: (1) the sequence and orientation within the heart of the electrical stresses set up, (2) the spread of the electrical currents generated by the heart in the body as a whole, and (3) the influence on the electrical field which results from the variable electrical conductivity of the tissues immediately adjacent to the heart.

While considerable attention has been paid in the past to the first two aspects of the problem, little thought has 
been given to the last phase. Not all regions of the heart are in contact with good conductors. It is obvious that those that are have a decided advantage over other regions of the heart in their influence on the electrical field. The various regions have been defined by us. Our work indicates that the variable electrical conductivity of the tissues in contact with the heart exerts a much greater influence on the electrocardiogram than the electrical conductivity elsewhere in the body.

In view of the above, it is apparent that changes in the electrocardiogram can result from variations in the relative position of the electrical conductors to the heart. This may be caused either by alterations in position or shape of the conductors adjacent to the heart or by changes in the position or shape of the heart itself. As a consequence, regions of the heart which normally exert a great influence on the electrocardiogram may become "silent," while other regions previously "silent" may now exert a prominent effect. We are presenting the experimental evidence which supports this concept.

Our results indicate that the electrocardiogram is not a summation of events occurring in all parts of the heart but is primarily a summation of events in those regions which are in contact with good electrical conductors. Other regions play a relatively minor rôle. This concept readily explains all the abnormalities of the electrocardiogram including some hitherto obscure ones. It also offers a rational basis for the use of precordial leads.

Changes in the Vaginal Smears of the Menopause during Periods of Spontaneous Symptomatic Relief. By Ephraim Shorr and (by invitation) George N. PAPANICOLAOU, New York, N. Y.

We have previously reported ${ }^{1}$ that adequate amounts of estrin administered to women with the menopausal syndrome changed the vaginal smear from that of the menopause to the leukopenic follicular type characteristic of the normally menstruating woman just prior to ovulation. This change was accompanied by symptomatic relief.

We have since observed four cases in which temporary spontaneous relief of their menopausal symptoms occurred. Studies of the vaginal smears revealed the fact that a change to the follicular type had spontaneously taken place at these times. There then followed a gradual regression of the smear to the menopausal type, with the reappearance of symptoms.

There was a complete similarity between the changes in smears and symptomatology during the periods of spontaneous relief, and those observed during the administration of ovarian follicular hormone. These observations suggest that the induction of the follicular smear type is a rational objective in the replacement therapy of the menopausal syndrome.

1 Papanicolaou, G. N., and Shorr, E., Proc. Soc. Exper. Biol. and Med., 1935, 32, 585.
The Relation of the Anterior Pituitary to Liver Glycogen Production and Utilization. By EDWARD D. CHURCHILL, Boston, Mass.

Rabbits six to eight weeks old were totally hypophysectomized. Baby rabbits were used because of their established reactions. Operative approach was through the nasopharynx, avoiding brain damage. The liver glycogen, blood sugar and lactate levels were studied under various conditions. Ten to twelve hours following glucose feeding a subnormal blood sugar plateau of 75 to 60 mgm. is reached. This plateau lasts four to six hours during which time the liver glycogen store gradually disappears. When the liver glycogen reaches a trace, 0.03 to 0.05 per cent, an abrupt fall in blood sugar starts. This fall is remarkably constant, occurring at the rate of about $10 \mathrm{mgm}$. per hour until convulsive levels are reached. It closely resembles the fall in blood sugar following hepatectomy. It is suggested that in the absence of the anterior pituitary, endogenous production of carbohydrate is so impaired that when the liver glycogen store is depleted the hypophysectomized animal is virtually hepatectomized. Intravenous glucose not only restores the blood sugar level but is readily deposited as liver glycogen. Intravenous sodium lactate in contrast to glucose is utilized but slowly. Adrenalin releases lactate but its failure to raise blood sugar is apparently in the lactate utilization.

Hypoglycemia. A Problem in Carbohydrate Metabolism. By Stanley E. Dorst, Cincinnati, Ohio.

An investigation of the varying response of adult malnutrition to insulin therapy reveals a group presenting an unusual problem in carbohydrate metabolism. These patients are undernourished and fail to show any permanent improvement under adequate dietary treatment. The glucose tolerance test shows a curious curve. Beginning at a subnormal fasting level the introduction of glucose either orally or parenterally is not followed by the expected increase in blood sugar, instead the values seldom rise above $100 \mathrm{mgm}$. per cent, nor do they drop below 60 even after 5 hours. No glucose is lost in the urine. This is definitely not the curve of hyperinsulism but resembles somewhat the configuration associated with hypothyroidism. These patients, however, have not had low metabolic rates.

With insulin therapy, paradoxically, the curve rapidly returns to the expected figures. There is rapid gain in weight, nervousness, asthenia and general malaise disappear. When insulin is withdrawn both the chemical and clinical picture reappears to respond again when insulin is resumed. Some of these patients have now been followed over 3 years.

All of our undernourished patients who have shown an adequate response to insulin therapy have fallen in this hypoglycemic group. Those who have a normal response to the ingestion of glucose have not shown clinical improvement on insulin therapy. These facts invite speculation and permit the introduction of certain theoretical concepts. 
Potential Variations of the Precordium and of the Extremities in Myocardial Infarction. By CharLes E. Kossman and Clarence E. de la Chapelle (introduced by Dr. Arthur C. DeGraff), New York, N. Y.

The potential variations of six precordial points and of the right arm, the left arm, and the left leg were recorded by the method of Wilson, Johnston, Macleod, and Barker in a series of 69 patients with myocardial infarction. In ten individuals who came to necropsy the gross and microscopic extent of the lesion was determined. The precordial electrocardiograms were similar to those obtained by Wilson and his associates in a study of experimental infarction with direct leads by the same method. The form of the initial and final ventricular deflections of the precordial curves depended upon the age and extent of the infarct, and the proximity of the exploring electrode to dead muscle, normal muscle, or combinations of the two. A true intrinsic deflection (chief upstroke) was absent when the exploring electrode was placed, (1) at a point on the precordium close to heart musculature which microscopically showed acute necrosis or replacement fibrosis of all or most of the muscle cells; (2) at the right sternal edge, the left sternal edge, and the tip of the ensiform in cases with extensive infarction of the left ventricular apex, the apical two-thirds of the anterior wall of the left ventricle, and the apical two-thirds of the anterior half of the interventricular septum, but with normal right ventricle; and (3) at the same points as in (2) in a case with extensive perivascular and interfascicular fibrosis of the entire left ventricle and septum due to coronary atherosclerosis and previous rheumatic myocarditis.

\section{READ BEFORE SECTION B}

Morphologic Changes in the Blood Associated with Experimentally Produced Hepatic Damage. By M. M. Wintrobe and (by invitation) H. B. Shumacker, JR., Baltimore, Md.

Acute and chronic hepatic damage have been produced in dogs and in rabbits by the administration of carbon tetrachloride. Following the initial doses of this drug, or after the dosage was abruptly increased, polycythemia developed. After injury to the liver was caused repeatedly and a chronic condition resembling cirrhosis was produced, anemia developed. This was often normocytic in type but in a number of instances in which the hepatic damage was particularly severe and of long duration, macrocytic anemia occurred. In the animals in which the latter type of anemia developed, the bone marrow was found to be hyperplastic.

The morphologic changes which occurred in the blood of the animals in these experiments resemble those which are found clinically in association with hepatic disease. The possibility that the macrocytic anemia may be the result of faulty storage of antianemic principle is considered.
The Coagulation of Blood by Proteolytic Enzymes. By H. EAGLe and (by invitation) T. Harris, Philadelphia, $\mathrm{Pa}$.

Trypsin and papain both coagulate whole blood and plasma. The latter acts directly on the fibrinogen, converting it to an insoluble modification resembling fibrin. Trypsin, however, has no direct effect on the fibrinogen, but converts prothrombin to thrombin.

The coagulation of blood by trypsin is therefore analogous to physiological coagulation, since the enzyme acts like the physiologic system calcium + platelets, in initiating the production of thrombin. There is reason to believe that calcium and platelets (or calcium and tissue extracts) together may constitute a proteolytic enzyme which either combines with or hydrolyzes prothrombin to form the physiologic coagulant, thrombin.

The Mechanism of Iron Transportation: Its Significance in Iron Utilization in Anemic States of Varied Etiology. By CARL V. MOORE (by invitation) and C. A. DoAn, Columbus, Ohio.

The mechanism by which iron is transported in the blood stream has consistently defied experimental definition. Three forms of blood iron have so far been recognized: (1) hemoglobin iron, (2) plasma iron, and (3) "easily split-off" iron, so termed because it may be "split-off" from hemoglobin by weak acids (Barkan). In association with, or as one of, the latter two forms, iron transportation is probably effected.

The present study emphasizes the extreme lability of plasma iron; the literature indicates the relative constancy of "easily split-off" iron; and both these forms are apparently independent of fluctuations in the hemoglobin content. In clinical states characterized by rapid destruction (e.g., congenital hemolytic icterus), and under conditions of diminished iron utilization (e.g., aplastic anemia and untreated pernicious anemia), the plasma iron has been found to be distinctly higher than its normal value of 75 to 150 micrograms per cent. Whenever the bone marrow was stimulated to unusually active erythrocytopoiesis as in liver induced remissions in pernicious anemia, there was a precipitous fall in the plasma iron level coincident with the reticulocytosis-iron presumably being withdrawn from the plasma more rapidly than it could be mobilized from the various storage depots. Iron deficiency states, whether of dietary, absorptive, or hemorrhagic etiology, have been attended by lower than normal plasma iron values. Oral administration of large single doses of iron has been followed by a temporary rise of the plasma iron to values as high as $\mathbf{5 0 0}$ micrograms per cent.

"Easily split-off" iron has been identified with the function of iron transport (Barkan), plasma iron being considered the medium of direct exchange with the tissues. However, in view of the relative constancy of its value, the known fluctuation in the iron content of the various storage depots, and the above described lability 
of plasma iron in terms of iron intake and utilization, it is logical to conclude that iron is transported primarily as plasma iron. The physiological significance of "easily split-off" iron remains yet to be defined.

Treatment of Pernicious Anemia with Congo Red. By HaLSEY Barker (introduced by C. P. Rhoads), New York, N. Y.

Mazza and Zolezzi, as well as Mermod and Dock, have reported that Congo red solution parenterally administered is effective in the treatment of pernicious anemia. Experiments designed to test the efficacy of Congo red in maintaining cases of pernicious anemia in remission have been made. A group of patients was kept symptom-free and at high blood levels by liver extract administered intramuscularly at 2 -week intervals. Liver extract was then discontinued and 0.5 per cent Congo red solution was administered weekly intravenously in $20 \mathrm{cc}$. amounts. In every instance a progressive increase in the mean corpuscular volume and the color index resulted, as well as a decrease in the number of erythrocytes and a recurrence of symptoms. Two cases of sprue recurred similarly. One case of pernicious anemia at a low blood level failed to improve on the daily administration of a small amount of liver extract. The evidence indicates that Congo red is not an effective substitute for liver extract in the treatment of pernicious anemia.

The Coproporphyrin of the Urine and Feces under Normal and Pathological Conditions. By CECIL JAMES Watson (introduced by H. A. Reimann), Minneapolis, Minn.

1. Coproporphyrin I (configuration not corresponding to hemoglobin) was isolated from normal urine, and in increased amounts from the urines of the following instances: (a) Hemolytic jaundice of acquired type. (b) Fever due to lung abscess and empyema. (c) Cincophen cirrhosis of the liver.

2. Coproporphyrin III (configuration corresponding to hemoglobin) was isolated from the urines of three cases of lead poisoning.

3. Coproporphyrin I was isolated from normal feces and in increased amount from the feces of patients with hemolytic jaundice. Coproporphyrin I was also obtained from the feces of a case of lead poisoning during the same period in which the urine yielded only the isomeric coproporphyrin III.

Coproporphyrin III is regularly excreted in the urine in lead poisoning, and probably owes its formation to a peculiar disturbance in hemoglobin metabolism. Coproporphyrin I, whose formation is by independent synthesis, occurs in the normal urine and feces in small amount. It is increased in the feces in hemolytic jaundice and pernicious anemia (previous report) and in the urine in conditions exhibiting evidence of liver dysfunction, notably urobilinuria.
Deficiency of Plasma Magnesium and Excess of Plasma Potassium in Essential Epilepsy. By ArThur D. HirschFelder and (by invitation) VICTOR G. HAURY, Minneapolis, Minn.

Having reported previously a group of clinical cases with low plasma magnesium in all of whom neuromuscular twitchings or convulsions were present, we have determined plasma magnesium in cases of essential epilepsy at the Minnesota Colony for Epileptics (Cambridge, Minn.), using a slight modification of our Titan Yellow colorimetric method. In normal individuals we found plasma magnesium 1.8 to $2.4 \mathrm{mgm}$. (average $2.11 \pm 0.11$ mgm.) per 100 cc. plasma, ultrafiltrable magnesium (through number 300 sheet cellophane) 0.9 to $1.3 \mathrm{mgm}$. (average $1.08 \pm 0.12 \mathrm{mgm}$.). We found low plasma magnesium during convulsions in 65.6 per cent of 32 severe epileptics and in 40 per cent of 35 less severe epileptics. The lowest magnesium (1.2 to $1.5 \mathrm{mgm}$.) occurred only in the most severe cases. In 78 out of 79 cases the magnesium was normal in the interim between periods of convulsions when the patients had been free from convulsions for at least several days, but magnesium was sometimes low just before or just after convulsions.

Plasma potassium (average normal $20.85 \mathrm{mgm}$. K per $100 \mathrm{cc}$. plasma) was more than double the normal during convulsions in 71.9 per cent of the severest cases and in 56 per cent of the moderately severe cases, and was but slightly above normal in the milder cases.

The potassium/magnesium ratio was above normal in all 67 cases during the convulsions, more than double the normal in 71.9 per cent of the severest cases and in 20 per cent of the moderately severe, but only slightly above normal in the mildest cases. The Ultrafiltrable K/Ultrafiltrable $\mathrm{Mg}$ ratio was increased more intensely than the Total $\mathrm{K} / \mathrm{T}$ Total $\mathrm{Mg}$ ratio.

There were no critical levels of either magnesium, potassium or $\mathrm{K} / \mathrm{Mg}$ ratio at which convulsions were certain to take place or to be absent.

Since Hirschfelder has shown that potassium salts antagonize the narcotic effects of magnesium salts it is probable that low plasma magnesium, high potassium, and especially high potassium magnesium ratios are important contributing factors in bringing on the convulsions of essential epilepsy.

Plasma calcium was always normal, phosphate was sometimes moderately increased (to 6 to $8 \mathrm{mgm}$.) during the convulsions but much less frequently and less intensely than the potassium; hypoglycemia was never present before, during or after the convulsions, but blood glucose increased moderately during convulsions.

Oral administration of 2 grams $\mathrm{MgCl}_{2}$ four times daily for three months did not diminish the frequency or intensity of the convulsions nor did oral administration of 2 grams $\mathrm{KCl}$ four times daily increase them. Rectal enemas of 30 grams epsom salt usually and intramuscular injection of 1 gram epsom salt almost always inhibited convulsive seizures. 
The Effect of High Protein Diet and Intraperitoneal Injection of Ringer's Solution on Renal Hypertrophy after Unilateral Nephrectomy in Rats. By PAUL L. Stier (by invitation) and J. M. Hayman, JR., Cleveland, Ohio.

The observation that rats ingesting a diet containing large amounts of protein show an increase in kidney weight has been made repeatedly. These animals drink much water and excrete a large volume of urine. The question, therefore, arises whether the increase in kidney weight is related to the excretion of the larger amounts of fluid. After unilateral nephrectomy, white rats of approximately the same age were divided into three groups. One group was fed a low (18 per cent) protein diet, the second a high (67 per cent) protein diet, and the third the low protein diet plus daily intraperitoneal injections of Ringer's solution in amounts comparable to the urine volume of animals on the high protein diet. After 40 days, the animals were killed, and the increase in kidney weights compared. The rats on the low protein diet showed a mean increase of $\mathbf{5 2}$ per cent in kidney weight, those on the high protein diet a mean increase of 116 per cent, and those receiving Ringer's solution 66 per cent. The excretion of increased volumes of urine is apparently not an important factor in the renal hypertrophy following high protein diets.

The Concentration of Urate in Cells and Plasma as a Function of $\mathrm{pH}_{8}$. By JoHN H. TalbotT and (by invitation) Jane M. Sherman, Boston, Mass.

The distribution of urate between cells and plasma as a function of the hydrogen ion concentration has been studied in the blood obtained from 3 patients with gout. In all instances venous blood was used, samples of which were equilibrated at $37.5^{\circ} \mathrm{C}$. in a water bath at varying tensions of $\mathrm{CO}_{2}$. The hydrogen ion concentration was calculated according to the Henderson-Hasselbach equation. In all of the experiments reported at this time the concentration of urate in plasma, cells and whole blood was determined colorimetrically according to the method of Benedict. ${ }^{1}$ Chloride and water concentrations were determined simultaneously with urate in plasma and cells. The distribution of urate and chloride between plasma and cells was calculated according to the equation,

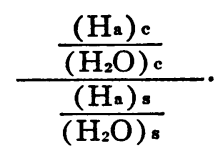

In 3 experiments the urate concentrations were determined at varying hydrogen ion concentrations in blood to which no uric acid was added. With increasing acidity there was a diminution in concentration of urate in the plasma and an increasing concentration of urate in the cells. The average diminution in plasma urate concentration over a $\mathrm{pHs}$ change of 1.0 was $2.3 \mathrm{mgm}$.

1 Benedict, S. R., and Behre, J. A. J. Biol. Chem., 1931, 92, 161. per $100 \mathrm{cc}$. This percentile change is large and approximately ten-fold greater than the change in water concentration.

In 3 other experiments 8 to $10 \mathrm{mgm}$. of uric acid per $100 \mathrm{cc}$. were added to whole blood. In these, the average urate ratio between cells and plasma at $\mathrm{pH}_{\mathrm{s}}=7.40$ was 0.58 . At the same $\mathrm{pHs}$ the chloride ratio was 0.64 . The change in the urate ratio with $\mathrm{pH}_{\mathrm{s}}$ followed closely the change in the chloride ratio.

In one experiment the urate and chloride ratios were determined for oxygenated and reduced whole blood. At $\mathrm{pHs}_{\mathrm{s}}=7.80$ the spread between oxygenated and reduced whole blood for the urate ratio was 1.0 and for the chloride ratio was 0.8. At $\mathrm{pH}_{8}=6.90$ the spread for the urate ratio was 0.2 and for the chloride ratio was 0.2 . These data are interpreted to mean that the distribution of urate between cells and plasma is affected by the Gibbs-Donnan law of equilibrium.

Comparative Biological Effects of Neutron Rays and XRays. By John H. Lawrence and ERnest O. LawRENCE (introduced by Francis G. Blake), New Haven, Conn.

In a previous paper it was demonstrated that neutron rays are biologically active, as determined by studying the fall in the number of white blood cells in rats after irradiation. Other animals were irradiated with high voltage $\mathrm{x}$-rays. Using the roentgen unit, as a measure of dosage for both neutrons and $x$-rays, the neutron seemed to be more effective than $x$-rays. This was not surprising, since the ionization in tissues by neutrons is probably produced by recoil protons, which are heavy charged particles, when compared with electrons.

In the present work we have studied further the comparative effects of neutrons and $\mathrm{x}$-rays on tissues, as measured by the lethal dose for mice and rats, and the lymphopenia produced in the rat. The results indicate that neutrons are much more biologically active than $\mathrm{x}$-rays.

Studies on the Relationship of the Hypophysis to Hematopoiesis. By OvID O. MEYER and (by invitation) Gertrude E. Stewart, and Harold P. Rusch, Madison, Wis.

It has been found that hypophysectomy in rats is followed by a persistent subnormal reticulocyte count in the peripheral blood. When these hypophysectomized animals are exposed to a reduced atmospheric pressure, no reticulocytosis occurs though sharp increase in the controls is regularly observed. Exposure to reduced pressures soon after hypophysectomy is followed by polycythemia comparable to that of the controls but none occurs after a 25-day postoperative period. The bone marrow does not become hyperplastic as in the controls. The results in animals that have been splenectomized before hypophysectomy are analogous to those with spleen intact.

Though the stimulus of oxygen want and the administration of liver extract do not produce an increase in 
reticulocytes, the administration of large doses of antuitrin (growth hormone) is followed by marked reticulocytosis in every animal, reaching a maximum of 15 per cent in one instance. There is, however, persistent anemia unless thyroxin is administered with the growth hormone.

Thyroidectomized and orchidectomized rats respond to oxygen want in a manner analogous to that of normal animals.

Quiet Breathing in a Closed Circuit, with Progressively Decreasing Oxygen Concentrations: Effect upon Composition of Expired Air. By D. W. Richards, JR., and (by invitation) H. C. A. LAssen and A. CourNAND, New York, N. Y.

When a normal resting subject breathes through a small closed circuit with progressively decreasing oxygen concentration, it is found after several minutes that the nitrogen concentration of an expired air sample, taken at the end of an expiration, is about 1 per cent less than the nitrogen concentration of the immediately preceding inspired air. The calculated oxygen utilization is also small, with R.Q. values well over 1.0.

When the same system is arranged so that the inspired air either maintains a constant composition, or has a steadily increasing oxygen concentration, the nitrogen concentration of expired air is then about 1 per cent greater than that of inspired air, as one would expect.

The explanation is probably this. Each inspired breath is added to a relatively large volume of (functional) residual air. Each expired breath is a mixed sample of air from this residual lung volume, and contains air from a number of earlier inspired breaths. With progressively decreasing inspired oxygen, the expired samples thus tend to have relatively higher oxygen concentrations, and lower nitrogen concentrations, than those of the immediately preceding inspired air.

In the breathing system described, therefore, the complete and equal mixing of an inert gas, which has often been assumed, does not actually exist.

\section{READ BY TITLE}

Anticomplementary Wassermann Reactions Associated with Hyperproteinemia, particularly in Lymphogranuloma Inguinale and Multiple Myeloma. By AlexANDER B. GutMan and (by invitation) Russell D. WiLLIAMS, New York, N. Y.

Williams and Gutman called attention recently to the occurrence of hyperproteinemia in lymphogranuloma inguinale. Values of 8.0 to 11.2 per cent, due chiefly to hypereuglobulinemia, were found in 16 of 20 cases examined. It was noted, further, that the Wassermann reaction was reported as anticomplementary in 22 per cent of 74 Frei-positive patients, as compared with approximately 1 per cent in the general hospital population. This association suggested the possibility of a similar relationship in other diseases in which hyperproteinemia occurs.

It was found that in 2 of 3 cases of multiple myeloma with hyperproteinemia, but in none of 4 without hyperproteinemia, anticomplementary Wassermann reactions were obtained (cf. Magnus-Levy). We have observed, also, anticomplementary Wassermann reactions associated with hyperproteinemia in occasional cases of tuberculous lymphadenitis, non-specific infections, lymphosarcoma, pregnancy. In kala-azar, moreover, in which hyperproteinemia is the rule, $\mathrm{Mu}$ and Huie report anticomplementary Wassermann reactions in 16 per cent of their cases.

There is evidence, presumptive and experimental, to indicate that increased serum globulin, particularly in the euglobulin fraction, is one of the important factors associated with non-specific fixation of complement in man.

Persistent non-specific fixation of complement, whether observed in the course of the Wassermann reaction or in the gonococcal-complement fixation test, may, in our experience, occasionally prove of diagnostic value.

Influence of Nutrition and of Pancreatectomy on Resistance to Experimental Septicemia. By RUSSELL Richardson (introduced by C. N. H. Long), Philadelphia, $\mathrm{Pa}$.

This study was designed to correlate the recognizable changes in blood and tissue chemistry occurring in experimental diabetes under varying conditions of nutrition with the duration of life and the degree of bacteremia following a standard infection with staphylococcus aureus.

The experiments have been conducted on 45 cats : 25 depancreatized, 11 on liberal diet and insulin, 14 on restricted diet with minimal dosage of insulin; 20 control cats, 13 on unlimited diet, 7 on restricted diet.

The procedure has been: (1) preliminary period on the selected diet in the control and depancreatized animals. (2) Examination of blood for concentration of sugar and serum for concentration of $\mathrm{CO}_{2}$ and refractive index, and of muscle and liver for glycogen content; in some experiments measurements were made of cholesterol, albumin, total protein and water content of serum and of glycogen content of skin and spleen. (3) Inoculation of controls and depancreatized cats with standard dose of staphylococcus aureus. (4) At daily intervals until death, blood culture with bacterial count and repetition of the examinations of blood and tissue chemistry. (5) Record of the duration of life after inoculation.

The correlations observed and inferences that can be drawn will be presented.

Renal Physiology in Lobar Pneumonia. By LEE E. FARR and Theodore J. Abernethy (introduced by Rufus Cole), New York, N. Y.

The immediate and delayed effects of pneumococcus pneumonia upon renal function were studied in twentyfive unselected patients. Urea clearances were done on admission, at crisis, five days postcrisis and at intervals following discharge for six months. Addis sediment counts were done on admission, at crisis and six days postcrisis. Frequent retinal examinations, daily blood 
pressure and quantitative urinary protein estimations were made. During hospitalization, fluid intake and output were measured. Occasionally urine chlorides were determined.

Results: Urea clearance varied inversely with age. Eleven patients ten to twenty-nine years old showed an average elevation, during precritical and immediate postcritical phases, to 147 per cent normal, returning slowly thereafter to normal. Five patients thirty to thirty-nine years old showed a precritical average of 109 per cent normal, a postcritical average of 115 per cent. Five patients forty to forty-nine years old averaged 98 per cent before crisis, 55 per cent after crisis, returning to normal during late convalescence. Five older patients, fifty to sixty-five years old, averaged 83 per cent precritically and 77 per cent postcritically. No significant increase of urinary .protein or formed elements, no hyperpiesis or retinopathy were observed.

The relationship of these findings to renal physiology is discussed.

Bacterial Hypersensitivity Due to the "Normal Flora." By Stanley Dorst, Cincinnati, Ohio.

The practice of employing intradermal tests in the selection of antigens from a mixed flora has become increasingly common in vaccine therapy. It has long been recognized that reactions similar to the tuberculin reaction may follow the intradermal injection of many bacteria and bacterial by-products. There is, however, differing opinion when one presumes to attach the same significance to these reactions that one attaches to the tuberculin reaction, namely that they indicate bacterial hypersensitivity. The objection seems to center around the fact that so many persons react to members of their so-called normal flora.

After studying such reactions for some ten years, occurring in over 2,000 patients, we have come to the conclusion that they do indicate hypersensitivity. This has led us to postulate that many persons suffering from illnesses for which we have a very insecure pathological background are the victims of sensitization to organisms belonging to the assumed normal flora. There is present conclusive evidence that such reactions occur with frequency. Evidence accumulated during the desensitization of such individuals supports the thesis that we are dealing with true and specific bacterial hypersensitivity. We desired additional confirmation. Such confirmation has been afforded by experiments showing that the specific soluble carbohydrate of antigens belonging to the normal flora produce strain-specific reactions in persons reacting to the whole antigen, resembling in this respect, the reactions to $B$. tuberculosis and the pneumococci.

It would seem that the term normal flora may be open to a different interpretation than the one which commonly prevails.

The Effect of Certain Cardiac Glucosides on the Frog's Heart. By A. G. MACLEOD, New York, N. Y.

The purpose of the investigations was to determine the effect of certain pure cardiac glucosides on the funda- mental properties of heart muscle. The drugs were given intravenously to large frogs, and the action currents obtained by means of a simultaneous record of a cephalad-caudad lead and a direct lead from the surface of the heart. Heart block of two kinds occurred, auriculoventricular and ventriculo-conal. The latter usually occurred before the former. The most important effect however was a very marked shortening of the secondary deflections of both auricle and ventricle; the R-T segment of the electrocardiogram consequently became very short. The refractory period shortened pari passu with the secondary deflection. Ectopic rhythms occurred as a result of this which simulated fibrillation and flutter. The effects of the drugs were uninfluenced by atropine. The speed of onset and the duration of the effects varied with the different drugs. A correlation between these results and certain clinical phenomena can be made.

The Tolerance of Certain Cardiac Patients for Various Recumbent Positions. By Francis Clark Wood and Charles C. Wolferth, Philadelphia, Pa.

Certain cardiac patients who can lie comfortably in one horizontal position (usually the right lateral), cannot tolerate another horizontal position (usually the left lateral), and are forced to abandon the latter for the former by symptoms which cannot be endured. No reference to this fact has been found in the literature. The phenomenon is quite common. It is seen in patients with cardiac enlargement who are in or near congestive failure.

The symptoms which compel a patient to abandon one horizontal position for another are the same as those which force an orthopneic patient to sit up-especially shortness of breath, precordial discomfort, and cough. A severe paroxysm of dyspnea may occur if the unfavorable position is too long maintained. This phenomenon cannot be accounted for by vital capacity changes, nor by the variations in relative levels of right auricle and respiratory center.

Our observations suggest (1) that change of position of the heart (demonstrated roentgenographically) with consequent distortion of the great vessels, may be concerned in its production, and (2) that this factor should be considered in the explanation of orthopnea and paroxysmal nocturnal dyspnea in cardiac patients.

The Work of the Left Ventricle in Aortic Insufficiency. By Еммeт B. BAy (introduced by C. Phillip Miller, Jr.), Chicago, Ill.

To calculate the work done by the left ventricle in the presence of aortic insufficiency it is necessary to estimate its stroke volume output. A formula has been derived from theoretical considerations of the relationships between peripheral pressure and volume flow which gives an approximation of the volume regurgitated with each diastole. In a model of the circulation the formula gives results comparable to precise determinations of aortic leaks.

The amount regurgitated per beat plus the observed stroke volume is the actual systolic discharge. This total 
stroke volume multiplied by the systolic arterial pressure in proper units is a close approximation of the work per beat of the left ventricle in this valvular lesion.

Calculations based on estimations of the amount regurgitated with various hypothetical stroke volumes and arterial pressures in human aortic insufficiency give a conception of the relative work of the left ventricle in that disorder.

Undernutrition in the Treatment of Coronary Artery Disease (Particularly Thrombosis). Effect on the Basal Metabolism and Circulation. By A. M. MASTER, H. L. JAFFE and S. DACK (introduced by George Baehr and B. S. Oppenheimer), New Yotk, N. Y.

The effect of low caloric intake on basal metabolism and circulatory dynamics was investigated in 29 cases of coronary thrombosis and 13 of angina pectoris. An 800 calorie diet, 80 grams carbohydrates, 50 proteins and 30 fat, was maintained for 3 to 12 months. The control basal metabolic readings lay within +10 and -10 . In 74 per cent, a significant fall in basal metabolism of 15 to 35 per cent occurred in two to four weeks. The causes for failure of the metabolism to fall significantly were repeated angina pectoris, fever, pulmonary disease and cardiac insufficiency. The factors influencing metabolism in heart disease were studied. An increase in caloric intake effected a rise in metabolic rate. The loss of weight associated with the drop in metabolism averaged 6 per cent of initial body weight. The blood chemistry remained unchanged; no myxedema appeared.

The effect on circulation of the low caloric intake with its resultant drop in metabolism consisted of slowing of pulse rate and fall in blood and pulse pressures. The cardiac output (determined in one case) was reduced 33 per cent. All these factors resulted in reduction of the work of the heart. The blood velocity and vital capacity remained unchanged.

Clinical Observations Bearing on the Selection of Cases for Surgical Treatment of Essential Hypertension with Results in Twenty-Four Cases. By RoBert STERLING Palmer and (by invitation) Reginald H. Smithwick, Boston, Mass.

Clinical observations of 224 cases of abnormally elevated blood pressure followed for varying periods during the past five years are reported. A special attempt has been made to find cases among young adults and cases in which an elevated blood pressure was an incidental finding, in order to study the development of essential hypertension of varying degrees of severity at different ages.

Considering the group as a whole, cases fall into mild, moderate, and severe. The mild cases have lower pressures which are variable, often returning to normal, are free from organic change, tend to occur in younger patients, possibly more often in males. Moderate cases have higher pressures, variable but less apt to return to normal, often have asymptomatic organic changes, and occur at somewhat older ages. Severe cases have the high pressures which, though just as variable as the mild or moderate, never return to normal, have marked organic changes with symptoms of circulatory insufficiency in brain, eyes, heart, or kidneys, and tend to occur at older ages with one notable exception: the most severe cases, in the accelerated malignant phase occur under 50 years of age and in our experience most of them in females before the menopause. We have observed occasional cases pass from one stage to another, the first being marked by functional nervous symptoms sometimes related to difficulties of emotional nature and accompanied by a variable hypertension, which later though still variable, attained a higher level. In one patient the course from a mild variable hypertension to intractable malignant hypertension and death occupied three years.

As a working hypothesis we suggest that essential hypertension may be related to a constitutional susceptibility or irritability of the sympathetic adrenal system. Precipitating factors in the latter state may be nervous tension and endocrine abnormalities in females. Clinical observation indicates that many cases pass through a mild predominately vasomotor, stage offering an opportunity for cure or alleviation by surgery of the sympathetic nervous system when medical management fails to halt the progress.

In view of our clinical observations and with this working hypothesis we have employed various surgical procedures in 24 cases; in severe cases because of distressing symptoms and the hopeless prognosis, in moderate cases because observation indicated progress, in mild cases because the pressure was not controlled by medical measures and because the patients fell into a prognostically bad group (females of child-bearing age).

Our results are as follows: Six patients (5 severe, 1 mild) were subjected to alcohol injection of the splanchnic nerves. A temporary (days to weeks) fall in blood pressure was obtained. A disproportionate symptomatic improvement was noted. Adrenal denervation or adrenalectomy was done in 4 severe cases and 1 mild case of essential hypertension. A temporary fall in blood pressure was the result. Symptomatically improvement was noted and in one case marked improvement in the eye grounds was observed. Three severe cases were subjected to splanchnic resection without any permanent benefit. Finally 9 cases ( 6 severe, and 3 mild) have had supradiaphragmatic splanchnic resection. Of the six late cases a material reduction in blood pressure has been observed in 3 with decreased fluctuation in 4 , but no return to normal. All 3 of the mild cases have shown material lowering of the blood pressure, 2 to normal levels, stabilization of the blood pressure in 2, decreased fluctuation in the third. One case of malignant hypertension has had laminectomy and anterior root section recently, and it is too soon to report results.

We have not taken symptomatic improvement as a criterion of success because we seek to prevent the more or less remote results of continued arterial hypertension, because incidental operations such as cholecystectomy cause a temporary fall in blood pressure and symptomatic improvement. However, diminution in fluctuation of the 
blood pressure may be of palliative value in moderate or severe cases when organic change precludes the hope of markedly lowering the blood pressure.

Our limited experience with laminectomy and anterior root section leads us to believe that the operative mortality and the chance of postoperative complications is too great for any but the most hopeless cases.

The Behavior of Human, Bovine and Avian Tubercle Bacilli in Media Containing Sulphur. By Burgess L. GorDon and (by invitation) R. C. RosenberGER and A. Proskouriakoff, Philadelphia, Pa.

Preliminary studies suggest that the addition of $4 \mathrm{mgm}$. of elementary sulphur to $100 \mathrm{cc}$. of Corper's medium prevents the growth of tubercle bacilli. It appears also that sulphur exerts a bacteriostatic influence.

Volumetric Studies of the Circulation in a Sharply Defined Portion of the Human Finger Tip. ${ }^{1}$ By W. A. Sodeman and G. E. Burch (by invitation) and R. H. TURner, New Orleans, La.

Using a sphygmoplethysmograph sensitive to 0.1 cubic millimeters, we have measured changes in volume of a sharply defined portion of the human finger tip in response to the pulse and to changes of position of the finger from heart level to a position $45 \mathrm{~cm}$. above and $45 \mathrm{~cm}$. below heart level and changes due to sudden application of pressure within a sphygmographic cuff about the upper arm while the finger was in an elevated position. The part studied reached its minimum volume while in the elevated position following pressure occlusion of the arm vessels. For the purpose of our calculations, the finger tip was assumed to be bloodless when it reached its minimum volume. All volumes above this base line were accepted as representing the total blood volume of the part at that stage of the observation. The volume of soft tissue was also determined, thus enabling the expression of blood volume in terms of per cent of soft tissue.

The subjects studied have all been adult males, ranging from 20 to 70 years of age, including the following: 17 normal individuals, 6 suffering from diastolic hypertension, 9 showing arteriosclerosis alone, 9 with arteriosclerosis and diastolic hypertension, and 2 with congenital clubbing of the fingers.

Our data indicate: $A$. In patients with arteriosclerosis without diastolic hypertension, the mean volume of pulsations was approximately that of the normal; the mean total blood volume was reduced; and the volume of pulsations, expressed as per cent of total blood volume, was increased. The extremes of individual variations of the total blood volume in patients with arteriosclerosis without diastolic hypertension were greater than in the normal group.

$B$. In patients with diastolic hypertension, the volume

1 Aided by grants from the Josiah Macy, Jr. Foundation, the David Trautman Schwartz Research Fund and the American Medical Association. of pulsations and total blood volume at heart level were reduced. In the elevated position the total blood volume was approximately that of the normal group but the volume of pulsations was again reduced. In the lowered position the total blood volume was reduced while the volume of pulsations approximated that of the normal group. In all positions the volume of pulsations, expressed as per cent of the total blood volume, was about the same as normal. The range of individual determinations of the volume of pulsations, total blood volume, and volume of pulsations expressed as per cent of total blood volume at heart level, was greatly limited as compared to the normal and arteriosclerotic groups.

$C$. In patients with arteriosclerosis and diastolic hypertension, the mean volume of pulsations, total blood volume and volume of pulsations, expressed as per cent of total blood volume, in general fell between the values obtained in patients with these diseases separately.

$D$. In a patient with localized Raynaud's phenomenon (dead finger) with marked atrophic changes in the left index (affected) finger, distinct changes were noted at room temperature as compared to the corresponding normal (right index) finger. The involved finger showed a reduced total blood volume in all positions, out of proportion to the reduction in the total soft tissue volume. The volume of pulsations was slightly reduced at heart level and definitely so at the elevated and lowered positions. The volume of pulsations expressed as per cent of total blood volume was greater in the involved finger at heart level and the lowered position, but was less at the elevated position.

$E$. In two cases of congenital clubbing of the fingers, the volume of pulsations was markedly reduced in all positions and was affected negligibly by position. The total blood volume and the volume of pulsations expressed as per cent of total blood volume were relatively and absolutely reduced in all positions as compared to all other groups.

The Effect of Intramuscular Adrenalin upon the Heartrate in Psychoneurotic Patients. By Stanley COBB and (by invitation) JАСOB E. Finesinger, Boston, Mass.

Continuous records of heart rate were made by means of a cardiochronograph ${ }^{1}$ on thirteen patients with psychoneuroses of various types. The patients were made to stand up and lie down at regular intervals before and after the intramuscular injection of adrenalin (ParkeDavis) in doses varying from $1 / 2$ to $1 \mathrm{cc}$., 1 to 1,000 . The mean heart rate in beats per minute was read from the records. Before adrenalin the standing rate always exceeded the lying rate, the difference between the two varying from 15 per cent to 120 per cent. In addition to the accelerating effect upon both standing and lying rates, intramuscular adrenalin caused the lying rates to approach the standing rates and tended to obliterate at

1 Whitehorn, J. C. et al., Arch. Neurol. and Psychiat., 1935, 33, 713. 
least for a short time the percentage difference between the lying and standing rates observed before adrenalin. In six cases the percentage difference between lying and standing rates was reduced to zero or to a minus value (that is, the standing rate was equal to or lower than the lying rate). This reduction occurred between six and thirteen minutes after adrenalin. In four cases the lying and standing rates returned to their original values at the end of the experiment (twenty-three to ninety-two minutes after adrenalin). In three additional cases the standing rates alone had practically returned to their preliminary values. In the remaining experiments which lasted from forty to one hundred minutes after adrenalin the standing and lying rates were greater at the end of the experiments than before the administration of adrenalin.

Ascorbic Acid in the Treatment of Thrombocytopenic Purpura. By DAvid K. MilleR (by invitation) and C. P. Rhoads, New York, N. Y.

The effect of the administration of ascorbic acid has been studied in a group of patients with thrombocytopenia associated with bleeding into the skin and from the mucous membranes. No effect has been seen in cases which were diagnosed leukemia, aleukemic leukemia, or aplastic anemia. In four cases of apparently idiopathic thrombocytopenic purpura a persistent rise in the number of thrombocytes and complete relief of symptoms followed the administration of ascorbic acid. In two such cases the excretion of ascorbic acid was measured quantitatively in order to test the relative degree of saturation with vitamin $C$. In both instances clinical improvement and an increase in the number of thrombocytes were associated with an increased urinary output of ascorbic acid. The results suggest that ascorbic acid may be therapeutically effective in certain cases of thrombocytopenic purpura.

Direct Measurement of Blood Flow through the Kidneys of Unanesthetized Dogs. By A. Blalock, T. R. HaRRISON and (by invitation) M. F. MASON, Nashville, Tenn.

For the purposes of studying renal blood flow and oxygen consumption, the following technique has been used. At a preliminary operation, the two spermatic veins, the left adrenal vein and any other branches (except the right adrenal vein) draining into the renal veins or into the vena cava near the entrance of the renal veins have been tied. A metal marker is tied to the inferior vena cava about three centimeters below the renal veins. Several days after the animals recovered entirely a large thin-walled metal cannula is passed under novocaine anesthesia from the right external jugular vein down through the superior cava and into the inferior cava as far as the ligature. Several different methods were employed to prevent leakage and back flow around the cannula. The most satisfactory device has been a modified Morowitz cannula carrying two balloons, one of which lies below and the other above the renal veins. The position of the cannula has been checked by fluoroscopic examination. By inflation of these balloons it is possible to obtain, through the cannula, all the blood flow through the kidneys during a measured period of time. Analyses of the oxygen contents and capacities of this renal venous blood and of arterial blood allow one to calculate the renal oxygen consumption. Data for these functions in normal animals, in animals after unilateral nephrectomy, and following the administration of various drugs, are presented.

Arteriovenous Fistula: Diagnosis from the Oxygen Content of the Blood of the Regional and Proximal Deep

Veins. By BAYARD T. HORTON and (by invitation)

Grace M. Roth and Elizabeth McClay, Rochester, Minn.

The term "arteriovenous fistula" is used to designate any abnormal communication between an artery and a vein by means of which arterial blood enters the vein without passing through a capillary bed. The immediate receiving group of veins show an increase in oxygen content, which depends upon the amount of arterial blood shunted into them by way of the fistula.

Determinations of the degree of admixture of arterial and venous blood in the regional and proximal deep veins was carried out in sixty cases of arteriovenous fistula. In fifty of these cases the condition was congenital, and in six of these the fistula was intracranial. In the remaining ten cases the fistula was acquired.

Blood was collected under oil, and the oxygen capacity and content were determined by the Van Slyke gasometric method. In the intracranial group, blood was obtained from the internal jugular veins, and the mean oxygen saturation was greater than 90 per cent. In cases in which the fistula was in the upper extremities the average saturation was 89 per cent, in the lower extremities, 82 per cent.

When surgical exploration was carried out, similar postoperative determinations were made to evaluate the results of surgery.

The Influence of Laparotomy on the Gastric Motor Mechanism. By GerRGe M. CurTis and (by invitation) Lours E. Barron, Columbus, Ohio.

Using the balloon and kymograph method we have investigated the motor response of the stomach to various abdominal operations. Extended serial observations are reported on one patient with cholelithiasis for which cholecystectomy was done, and on three patients with indirect inguinal hernia. Studies were made in the morning about fourteen hours after the preceding evening meal. The usual duration of each experimental observation was approximately five hours. Adequate control studies were made prior to and again subsequent to each surgical procedure. The results were uniform.

In the patient with cholelithiasis, normal gastric motility was observed during the control period. It was possible to investigate the gastric motor response during biliary colic. This revealed continuous gastric motility 
throughout the observation period. Severe contractions were at times observed. Studies were resumed subsequent to cholecystectomy which was accomplished under gas-ether anesthesia. Daily observations revealed that there ensued intense gastric motility persisting for about ten days. This hypermotility was associated with epigastric distress, interpreted by the patient as "gas pains." The motility subsequently returned to normal.

Observations were likewise made on three patients prior to, during, and subsequent to herniorrhaphy. The motility during the preoperative control period was essentially normal. Studies were made on the morning of operation to note the effect of stress on the gastric motor mechanism. In certain instances these revealed hypermotility associated with mild epigastric distress. Kymographic records of gastric motility during herniorrhaphy conducted under spinal anesthesia demonstrated complete gastric inhibition. This persisted for about twentyfour hours, at which time the stomach regained its tonus. Forty-eight hours subsequent to herniorrhaphy there was gas-ether anesthesia. Daily observations revealed that this persisted for about ten to twelve days. Associated with the gastric hypermotility the patients complained of epigastric distress which they designated as "gas pains." The gastric motility of all patients eventually returned to normal.

Neurological Findings in Patients with Rheumatoid Arthritis. By Charles L. Short and (by invitation) $A_{L}-$ FRED O. Ludwig, Boston, Mass.

Towards the end of the nineteenth century, the neural origin of rheumatoid arthritis was upheld by many observers. The symmetry of the joint lesions, the atrophy of muscles and skin, and other sensory and motor phenomena including bulbar involvement were cited in evidence. Inconstant pathological changes in the cord and peripheral nerves were found. With the advent of bacteriology, this aspect of the disease has been largely overlooked.

We have attempted to reopen the subject in the present study. Symptoms and signs attributable to the nervous system have been recorded in a large percentage of 250 carefully studied patients. Examination of the spinal fluid in $\mathbf{5 0}$ patients in all stages has revealed no constant deviation from the normal. Such fluid has been injected intracisternally in cats, without subsequent evidence of disease of the nervous system or joints. Anterior horn cell degeneration has been found at autopsy in one patient who showed bulbar and spinal neuronitis before death and changes in the peripheral nerves in four.

It is hoped that further studies will enable us to interpret the significance of these findings. Greater interest is desirable in this neglected but important phase of rheumatoid arthritis.

The Etiology of the Anemia of Iron Deficiency. By Clark W. Heath and (by invitation) Arthur J. Patek, JR., Boston, Mass.

The iron requirement, or the demand for iron by the organism, should logically be considered first in the eti- ology of iron deficiency. A reduction of the supply of iron, in the form of reduced dietary intake, malabsorption, or both, is an important and often necessary factor, but theoretically cannot alone produce iron deficiency.

Study of the iron requirements for normal growth (in particular increasing blood volume) and menstruation discloses important facts which explain the appearance of iron deficiency anemia at different periods of life. In infancy, and after puberty total annual iron requirements are greatest and at these times iron deficiency frequently appears. The data explain the appearance of iron deficiency (1) equally in the two sexes during infancy; (2) in girls at puberty, when the annual requirement for iron is proportional to that for a normal pregnancy; (3) in women more commonly than in men, since in women the total requirement until the time of the menopause is about four times that of adult men. In adult men iron deficiency anemia has been observed by the authors only following blood loss. Pathological bleeding and pregnancy have been observed to be important additional factors in the etiology of iron deficiency anemia in women. Chronic, often obscure, pathological blood loss is practically always present in "idiopathic" hypochromic anemia.

Observations on the Mechanism of Recovery in Gonococcal Arthritis. By Wesley W. Spink (by invitation) and Chester S. Keefer, Boston, Mass.

A study of the mechanism of recovery in patients with gonococcal arthritis has included an analysis of the bactericidal action of whole blood on the gonococcus. Although the whole blood is capable of killing gonococci in large numbers, this bactericidal power resides in the serum. Washed luekocytes or heated serum possess little or no killing power.

The blood of patients with gonococcal metastatic lesions, as arthritis, tends to have a higher bactericidal power for the gonococcus than normal controls. Similar studies are being carried out with patients having only localized lesions such as urethritis. An attempt is being made to study the virulence of individual strains by this method.

The bactericidal power of a normal individual was not increased following repeated injections of a gonococcal filtrate. Intradermal and subcutaneous injections of a gonococcal vaccine in another normal control was followed by no increase in bactericidal action of the whole blood. Intravenous gonococcal vaccine resulted in a slight but temporary increase in the bactericidal power of a patient with gonococcal arthritis. The intravenous injection of a stock anti-gonococcal horse serum caused an immediate and marked increase in the killing power of the blood of another patient, but one of short duration.

Observations on the Mechanism of Muscular Twitchings in Uremia. By T. R. HARRISON and (by invitation) M. F. Mason and H. Resnik, Nashville, Tenn.

Muscular twitchings in uremic subjects have been ascribed in the past to phosphate retention, resulting in a 
deficit of calcium ions in the blood. The following evidence indicates that the twitchings are of central rather than peripheral origin:

1. Intracisternal administration of inorganic phosphorus to dogs causes marked twitchings, similar doses being entirely ineffective intravenously.

2. When large doses of inorganic phosphorus are given intravenously, the onset of twitchings is usually delayed until the content of phosphorus in the cerebrospinal fluid increases.

3. In dogs with experimental anuria following double nephrectomy or bilateral ureteral ligation, the development of muscular twitchings is related to increase in the phosphorus content of the cerebrospinal fluid rather than that of the blood.

4. Both in experimental and in clinical uremia muscular twitchings may be alleviated by the intracisternal administration of calcium salts in doses which are ineffective when administered intravenously.

Accumulation of inorganic phosphorus in the cerebrospinal fluid is not the only cause of muscular twitchings, which may occur when the phosphorus content of the blood and cerebrospinal fluid is at a normal level. In such instances, increase in the amount of guanidine-like substances in the blood has been demonstrated. Since these compounds produce marked twitchings when administered to normal animals it is believed that their presence may account for the neuromuscular irritability which occurs occasionally without phosphorus accumulation.

In the terminal stages of uremia, twitchings may be absent in spite of marked increase in the phosphorus content of the body fluids. Under these conditions high values for the free phenols in the blood have been found. We have shown that the previous administration of free phenols will prevent the muscular twitchings which are ordinarily produced by the intracisternal injection of phosphorus.

In conclusion it is believed that accumulation of phosphorus and of guanidine in uremic subjects tend to produce twitchings, and that retention of phenol derivatives tends to prevent them. Their presence or absence depends on the balance of these opposing factors.

The Lipiduria of Bright's Disease: Observations on the Urinary Excretion of Cholesterol, Lipid Phosphorus and Fatty Acids. By MAURICE BrUGER with the technical assistance of William Pearlman (introduced by H. O. Mosenthal), New York, N. Y.

In previous reports from this laboratory, we showed that in the urine of patients with Bright's disease, the cholesterol excretion paralleled the protein excretion. ${ }^{1}$ This problem has been pursued further and at this time, studies on the cholesterol, lipid $\mathrm{P}$ and fatty acid content of 27 urines obtained from nine patients with Bright's disease are reported. In two patients, serial determina-

1 J. Clin. Invest., 1934, 13, 714 ; Am. J. Clin. Path., 1935, 5, 504. tions of 13 specimens of blood and urine, collected simultaneously, were carried out over a period of more than two months.

The concentration of urinary cholesterol varied from a trace to $1.97 \mathrm{mgm}$. per cent, lipid $\mathrm{P}$ from 0.007 to $0.134 \mathrm{mgm}$. per cent, and fatty acids from 0.07 to 4.78 mgm. per cent. In general, the concentration of the urinary lipids paralleled one another closely, the cholesterol/lipid $\mathrm{P}$ and the fatty acid/cholesterol ratios remaining fairly constant. Apparently, the degree of proteinuria is not only an indication of the amount of cholesterol excreted in the urine, but of lipid $P$ and fatty acids as well. Serial blood and urine studies in two cases indicated, however, that alterations in the lipid $\mathbf{P}$ and fatty acid content of the blood were accompanied, with few exceptions, by similar changes in the concentration of these lipids in the urine, whereas the association between blood and urine cholesterol was not so evident.

Enterogenous Cyanosis with Met-and Sulphhemoglobinemia; Clinical and Spectrophotometric Studies. ${ }^{1}$ By Henry H. Henstell (by invitation) and William DAmeshek, Boston, Mass.

Spectrophotometric observations with the Hardy recording spectrophotometer in a woman with bouts of cyanosis and diarrhea revealed the presence of both metand sulphhemoglobin. Since no etiological agent was discernible and alternating diarrhea and constipation were present, the diagnosis of enterogenous cyanosis was made. Of 36 cases which have been reported since 1902, 23 showed sulphhemoglobin, 12 methemoglobin, and one both pigments.

An intimate relationship was evident between the appearance of diarrhea and subsequent appearance of abnormal pigment in the red cells. Disappearance of pigment always resulted in anemia which in turn was followed by reticulocytosis. The diarrhea was dependent upon a proctitis characterized by inflammation and pinpoint ulcerations of the rectal mucosa. A bland diet with milk seemed curative, but attempts at induction of the original disorder with high protein and high sulphur diets were unsuccessful at a time when the rectal mucosa was relatively normal in appearance.

This is the second recorded case in which both metand sulphhemoglobin were demonstrated and the first in which spectrophotometric studies were secured. Our studies further demonstrated the relationships of met- and sulphhemoglobin to each other and to the intestinal pathology. The blood studies revealed another cause for reticulocytosis.

Combined Cord Degeneration without Anemia: A Case Report with Studies Bearing on the "Intrinsic Factor" of Castle. By Walter Lincoln Palmer and (by invitation) RoBert T. Porter, Chicago, Ill.

In this paper an untreated case of subacute combined cord degeneration of three years' duration, without

1 This study was aided by a grant from the Proctor Fund, Harvard Medical School. 
anemia, with achlorhydria, and with a prolonged spontaneous remission of symptoms is reported. Two experiments designed to demonstrate the presence or absence of the antianemic "intrinsic factor" of Castle in the gastric juice of this patient are considered to have given negative results. Control experiments are cited, showing positive results with normal human gastric juice and a negative result in pernicious anemia, all in accord with the observations of Castle and his coworkers. We are unable to offer a completely satisfactory explanation for the absence of anemia, for the presence of the combined cord degeneration, or for the failure of the neurologic process to progress during the past two years. Our observations may be interpreted as in accord with either of two views: $(a)$ that combined cord degeneration may be a disease sui generis, or (b) that it is invariably a manifestation of the same basic disorder as that which causes pernicious anemia.

Renal Insufficiency from Blood Transfusion-Relation to the Urinary State. By Elmer L. DeGowin, W. L. RANDall, E. D. Warner and W. K. Hall (introduced by $\mathrm{H}$. M. Korns), Iowa City, Iowa.

Certain individuals developing hemolysis from blood transfusions, from quinine idiosyncrasy, or during the course of blackwater fever, die of renal insufficiency. In vitro, hemoglobin precipitates in slightly acid solutions. This is increased in amount in the presence of 1 to 2 per cent $\mathrm{NaCl}$. Transfusions of large amounts of dog hemoglobin into dogs with alkaline urines produce innocuous hemoglobinuria. Transfusions into dogs with acid urines produce nitrogen retention and, often, death in coma 4 to 10 days after transfusion. This phenomenon sometimes occurs after the first transfusion but may require several. This inconstancy indicates that the variability of electrolyte content of the urine is also a factor.

Histologic examination of the kidneys of dogs dying in coma shows the tubules to be plugged with pigment derived from hemoglobin. The glomeruli are normal, and the tubular epithelium little damaged. Study of human cases dying from transfusion anuria and from quinine hemolysis indicates degrees of nephropathy varying from extensive tubular necrosis with slight pigment precipitation to cases with little tubular damage and much obstruction from pigment. It seems probable that blockage of tubules by precipitation of hemoglobin in acid urine is responsible for some but not all of the cases of renal insufficiency mentioned.

Syphilitic Nephritis. By Warde B. Allen (by invitation) and BENJ. M. BAKER, Baltimore, Md.

The literature on the subject will be reviewed briefly and a critical discussion of the validity of the clinical diagnosis of "syphilitic nephritis" will follow. The pathological basis for syphilitic nephritis will be discussed. The clinical course of several patients who combine syphilis and nephritis will be illustrated by lantern slides. Conclusions will be drawn as to the rational treatment of patients who combine the two conditions.
Effect of Iodine on Heat Production in Simple Goiter. By BRUCE Werster and (by invitation) L. M. Wright, New York, N. Y.

Webster and Chesney in 1928, and Webster in 1929, showed that the administration of iodine to rabbits with large simple goiters resulted in a marked but temporary increase in heat production. It was suggested at that time that this might have a bearing on the production of the so-called "Jod Basedow."

Eight patients with large, recently developed simple goiters were subjected to daily determinations of basal metabolism for one week. They were then given potassium iodide in 1 gram doses daily. An average increase of 18 per cent in heat production occurred. The greatest increase occurred on the third and fourth day after the beginning of the administration of iodine. In spite of the continued administration of iodine, the heat production fell gradually to a level at or slightly above the initial control level. Continued administration of iodine produced no further increase. The same amount of iodine given to four control subjects caused no alteration in basal metabolism.

The average metabolism of 120 consecutive clinic cases of simple goiter was -12 per cent. After three to eight weeks of iodine therapy it was +4 per cent.

These results are compatible with our previous animal experiments. Iodine, administered to a patient with hyperplastic simple goiter causes a temporary outpouring of an excessive amount of thyroxin.

\section{Clinical Investigation of Patients with Long-continued, Low-grade Fever (Habitual Hyperthermia). By Ho- bart A. Reimann, Minneapolis, Minn.}

Twelve persons apparently in good health were intensively studied to determine the cause of low-grade fever, in some cases known to have been present for years. Most of them had visited a succession of physicians in a futile attempt to determine the cause of " $\mathrm{fe}$ ver." Most of them were regarded as tuberculous and three were confined in sanatoria but discharged as nontuberculous. Of the 12, 2 were found to be normal in all respects as far as could be determined except for temperature, which averaged between $99^{\circ}$ and $100^{\circ} \mathrm{F}$. These were regarded as instances of true habitual hyperthermia since this average temperature fell within the limits of normal temperature when calculated statistically. The remaining 10 were regarded as distinctly neurotic with evidence of hypochondria, emotional instability, vasocardiac lability, and other symptoms characteristic of neurosis. In all 12 persons the temperature level was uninfluenced by amidopyrine and usually depressed by opium in contrast with fever due to infection; the suspension stability of the blood and the leukocyte picture were normal, agglutinins and intradermal tests for typhoid fever, undulant fever and tuberculosis, and the Wassermann reaction were negative. In 2 patients the basal metabolic rate averaged -25 but was increased by thyroid extract without effect on the temperature.

There appear to be at least two groups of persons 
whose temperature may be elevated to fever level in the absence of infection or other organic disease. The first group are apparently normal persons whose temperature is normal for them; the second are those individuals regarded as neurotic whose temperature may be above the usually accepted level of $98.6^{\circ} \mathrm{F}$.

Serum Phosphatase in Diseases of the Liver and the Biliary Tract. By Charles A. Flood and Etrel Benedict Gutman (by invitation) and Alexander B. GutMaN, New York, N. Y.

Roberts (1933) claimed that the degree of elevation of serum phosphatase activity could be used to distinguish between jaundice due to extrahepatic biliary obstruction and catarrhal (or toxic) jaundice. Subsequent investigators report conflicting results.

Serum phosphatase activity was determined (by Bodansky's method) in 22 proven cases of obstructive and 33 cases of catarrhal or toxic jaundice. In all our cases of obstructive jaundice, the serum phosphatase exceeded 10 Bodansky units per $100 \mathrm{cc}$., and the ratio serum phosphatase/serum bilirubin exceeded 1.0. In 29 of the 33 cases of catarrhal or toxic jaundice, the phosphatase was less than 10 Bodansky units. These results suggest that serum phosphatase values $<10$ Bodansky units make a diagnosis of jaundice due to obstruction of the extrahepatic biliary tract unlikely. These observations correspond with findings recorded by others following experimental ligation of the common duct and experimental hepatitis in the dog.

In a group of 12 cases of cirrhosis of the liver the serum phosphatase varied widely without any obvious relation to the degree of jaundice.

It is difficult to reconcile the low phosphatase values usually obtained in toxic hepatitis with the view that this type of jaundice is fundamentally due to intrahepatic obstruction.

Effect of Inhalation of Oxygen under Positive Pressure on Pulmonary Congestion and Edema. By Alvan L. Barach and (by invitation) JoHn Martin, New York, N. Y.

The exudation of serum through the lung capillaries into the alveolar spaces may be prevented or made to disappear in certain instances by inhaling oxygen (or air) under 5 to $8 \mathrm{~mm}$. $\mathrm{Hg}$ pressure. This offers an opposing pressure to the increased pulmonary capillary pressure. The maintenance within the chest of a positive pressure retards the entrance of blood into the right heart, increases the peripheral venous pressure and slows the circulation time. The clearing of the edema as a complication of cardiac failure persists while the pressure is being applied. Clinical and experimental evidence is presented.

Immunization against Neoplasm: Its Effect on the Nitrogen Metabolism of the Host. By William T. Salter and (by invitation) ROBERT OsTER, Boston, Mass.

Ten years ago Dodds found that certain rats which resisted inoculation with neoplasms showed a low blood urea concentration after treatment with $\mathbf{x}$-ray. More recently, Andervont has demonstrated that inoculation of tumors into the tails of mice may confer immunity against subsequent inoculation even though the tails be amputated. It has been found that animals immunized by Andervont's method show the peculiarity in urea metabolism which Dodds described.

The fasting blood urea concentration of normal and tumor-bearing mice is about $30 \mathrm{mgm}$. per cent even after treatment with $x$-ray. Immune animals show the same blood urea until irradiated. Thereupon, blood urea drops steadily for three days to about $20 \mathrm{mgm}$. per cent, and climbs to normal in the course of the next week.

The excretion of nitrogen in the urine shows urea to be consistently about 82 per cent and ammonia about 8 per cent of the total nitrogen. This is true despite an excessive nitrogen excretion the day after $x$-ray treatment in both normal and immunized animals. The drop in blood urea, therefore, is not due to a failure of the normal urea-producing mechanism.

Studies of tissue urea (muscle, liver) are correlated with blood studies. The results are interesting because they connect immunity to malignant tissue with an effect of $\mathrm{x}$-rays.

\section{Variations in Arterial Elasticity as Estimated by Meas- urements of the Velocity of Transmission of the Arte- rial Pulse Wave. By J. Murray Steele, New York, N. Y.}

In preliminary studies of arterial elasticity as estimated from the rate of propagation of the pulse-wave, the procedure evolved for obtaining comparable data under different sets of conditions, together with a few of the variations observed, was thought worthy of comment.

The hot-wire sphygmograph (Bramwell and Hill) was employed. The procedure consisted merely in establishing for each subject under investigation, the relation between changes in velocity and diastolic pressure in the brachial artery. Various diastolic pressures were obtained by using positive and negative pressure within cuffs about the arm (Hemingway, McSwiney and Allison). In each case the velocity was found to increase regularly with increase in diastolic pressure. Subsequent variations in velocity from this relation either spontaneous or following procedures known to affect the peripheral circulation could then be evaluated even in the event of marked changes in diastolic pressure. Since after death the elasticity of an artery is, furthermore, remarkably constant for several days, relatively large and abrupt changes during life may be taken as evidence of change in tone of the muscular coats.

Viewed in this light the observed variations in velocity suggest that the tone of the larger arteries varies spontaneously somewhat from day to day; that moderate exercise does not at once affect it to any measurable extent, nor does heat applied directly. If sufficient heat is applied to the body to result in reflex or general dilatation of the peripheral arterioles, then the tone of the larger peripheral arteries also decreases. In two patients suffering from hypertension, the spontaneous changes in 
tone, as well as those following heat were more marked than in the normal individuals.

A Case of Carcinoma of the Liver with Prolonged Asymptomatic Hypoglycemia. By William BenNeTt BeAN (by invitation), and ReAd Ellsworth, Baltimore, Md.

The case was that of a 49 year old colored man with an adeno-carcinoma (bile duct) involving fully 80 per cent of the liver. He had a fasting blood sugar of 35 to $45 \mathrm{mgm}$. per cent without any symptoms or signs except once after fasting 27 hours, he had a typical "insulin" reaction (blood sugar $33 \mathrm{mgm}$. per cent). Sugar tolerance showed somewhat delayed removal of sugar from blood (opposite to islet tumors). There was no mobilization of glucose after adrenalin (moderate vascular response-control showed 50 per cent rise in blood glucose). Levulose tolerance test showed very slight rise in blood sugar. There was never clinical or laboratory evidence of jaundice, but there was retention of 33 per cent of bilirubin after 30 minutes. Bromsulphthalein showed 80 per cent retention in 35 minutes. Other data: Total protein 6.36 grams. $A / G=42 / 58$. Cholesterol $103 \mathrm{mgm}$. per cent. Urea $\mathrm{N}_{2} 25 \mathrm{mgm}$. per cent. Nonprotein nitrogen $40 \mathrm{mgm}$. per cent. Phenolsulphonphthalein test 25 per cent in 15 minutes, 70 per cent in 2 hours.

On the Nature of Insulin Resistance. By Samued SosKIN and (by invitation) M. David AllweIss, and I. Arthur Mirsky, Chicago, Ill.

It has been shown previously that the decreased carbobydrate tolerance occurring in toxemia is not due to a lack of insulin consequent to pancreatic damage but, as we have demonstrated, results from an interference with a homeostatic liver mechanism for blood-sugar regulation. Furthermore, a progressively increasing toxemic liver damage presents a characteristic cycle of events, as regards carbohydrate tolerance, which is not merely a progression from the normal to the increasingly abnormal.

In the present report it is shown that, under the same conditions of toxemia which lead to a diminished carbohydrate tolerance, there is also a diminution in the effectiveness of administered insulin. This "insulin resistance," in a progressive toxemia, is subject to and must be interpreted in the light of a cycle of events similar to that which occurs in the carbohydrate tolerance. The loss of liver glycogen reserves is an additional complicating factor.

It is concluded that these results are of value in the interpretation, and of practical importance in the treatment, of cases of "insulin resistance" and of certain cases of so-called hyperinsulinism which present themselves clinically.

Studies on the Nature of Arterial Hypertension. By Myron Prinzmetal and Ben Friedman (introduced by B. S. Oppenheimer), New York, N. Y.

The vascular hypertonus that causes arterial hypertension is to be explained by one of the following mechanisms: (1) Increase in vasoconstrictor impulses. (2) Circulating pressor substances. (3) An intrinsic disturbance in the vessels themselves.

The first factor has been ruled out by Prinzmetal and Wilson who found that anesthetization of vasomotor nerves in hypertension does not release the vascular hypertonus.

No increase in pressor substances in hypertensive plasma was found by perfusion of rabbits' ears. Moreover direct cross transfusions of over one-third of the blood volume between hypertensives and normals were performed; simultaneously, to avoid changes in blood volume. Since no significant change in blood pressure occurred in either group, it appears unlikely that circulating pressor substances cause hypertension.

This leaves the third possibility, namely a local disturbance in the vessels themselves, as the cause. Experiments indicate that this disturbance is associated with the inherent tonus of the vessels, which is present in denervated vessels perfused with Tyrode's solution.

These observations do not rule out the presence of a circulating substance, not pressor in itself, which may be the cause of the pressor mechanism locally in the vessels. The possibility of such a substance seems likely, especially in renal hypertension.

The Origin and Nature of Normal Synovial Fluid. By Marian W. Ropes (by invitation) and Walter BaUer, Boston, Mass.

Existing data pertaining to the physical and chemical properties of normal synovial fluid are too few to allow one to speak with any degree of certainty concerning either its nature or origin. Therefore, a very complete physical and chemical analysis of normal synovial fluid and arterial blood as obtained from normal cattle has been made.

From these data one learns that normal synovial fluid is a clear, viscid liquid which does not clot. It contains 131 nucleated cells per cubic millimeter. Specific gravity

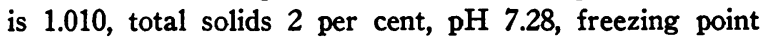
- $.535^{\circ}$, osmotic pressure against Ringer's solution 150 millimeters of water. Protein concentration is $1.0 \mathrm{gram}$ per 100 cc., of which one-eighth is mucin.

The concentrations of non-electrolytes are approximately equal in fluid and serum. The concentrations of chloride and bicarbonate are greater in fluid than in serum, while those of sodium, potassium, calcium and magnesium are less in fluid. The concentration of phosphate is approximately the same. The distribution ratios agree with those found for dialysates of blood plasma.

Studies reveal that the subsynovial vascular supply to the knee joint is rich, and in many instances the vessels are separated from the joint space by only a few layers of cells.

Thus, the chemical composition and anatomical arrangement are consistent with the theory that synovial fluid, like lymph and edema fluids, is a dialysate of blood plasma, to which is added mucin. 
The Response of Human Myxedema to an Artificial Thyroid Protein. By J. Lerman and W. T. Salter, Boston, Mass.

Six cases of human myxedema have been relieved by an artificial iodine-containing protein synthesized from human di-iodotyrosine peptone. The basal metabolic rate was used as the measure of potency. The rate of response for the artificial protein averaged 2.5 points (per cent of basal metabolic rate) per day as compared with 2.5 points for standard thyroxine polypeptide given in equi-iodine dosage.

The original di-iodotyrosine peptone produced no response in five patients with frank myxedema, in the same iodine dosage. When doses approximately five-fold were used, however, three patients responded satisfactorily. This effect is attributed to a thyroxine-containing impurity, probably thyroglobulin itself, on the basis of the following evidence. When filtered under 50 atmospheres of pressure through "cellophane" membranes, the original peptone failed in five-fold the standard iodine dosage to relieve three patients. Nevertheless, the artificial protein synthesized from this filtered peptone produced a standard response with standard iodine doses in two patients with myxedema.

The artificial protein ("plastein") behaved like natural thyroglobulin. It contained a thyroxine-like fraction which varied from 12 to 35 per cent of the total iodine. Its metabolic activity was much greater than that indicated by its thyroxine-like content. The latter itself, when isolated by drastic hydrolysis, relieved myxedema.

The Effect of Pregnancy and of Female Sex Hormones in Modifying the Course of Syphilis in Experimental Animals. By Jarold E. KeMP (introduced by Joseph E. Moore), Chicago, Ill.

In 1921 Brown and Pearce reported appreciable alteration in the course of early syphilis in a group of rabbits bred and inoculated simultaneously. This has since been used as experimental confirmation of the clinical assumption that the modified course of syphilis in women is due to pregnancy. The present study was undertaken to confirm Brown's findings and, on the assumption that they were correct, to determine whether or not the hormones found in the urine of pregnant women were the responsible agents.

A group of female animals was inoculated and bred simultaneously and rebred until they had experienced three pregnancies. Another group of twelve males and twelve females was treated daily with pooled pregnancy urine of high estrogenic titer for a period equalling the total duration of pregnancy in the preceding group. While there was marked alteration in the course of the infection in the pregnant group, no appreciable change in the treated groups was noted. The reasons for the difference between the behavior of these animals and those of Frasier which showed marked alteration in the course of the syphilitic infection after treatment with an estrogenic substance of lower titer and the modified course of syphilis in nonpregnant females are discussed.
The Role of the Pineal Gland in Growth and Development. By L. G. RowntreE, and (by invitation) J. H. Clark, Arthur Steinberg, N. H. Einhorn and A. M. Hanson, Philadelphia, Pa.

Pineal extract (Hanson) has been administered intraperitoneally daily to parent rats, and the effects have been followed through six generations. The result was a marked retardation in the rate of growth and marked acceleration in the rate of development-precocious "dwarfism" with relative macrogenitalism. The effects of pinealectomy were studied in four succeeding generations of parents. The results to date have been inconstant.

The Reticulocytosis of Fetal and Nursling Rats. Preliminary Report of a Method of Investigation of Some Factors Influencing Reticulocyte Maturation. ${ }^{1}$ By Thоmas Fitz-Hugh, JR. and (by invitation) AdolPH J. Creskoff and Helen B. Taylor, Philadelphia, Pa. Five living rat fetuses of different ages were extracted 2 from five mothers for blood study. The daily levels, from birth to twentieth day, were determined, of reticulocytes, erythrocytes and hemoglobin, of forty rats from fourteen litters. ${ }^{3}$ A virtually 100 per cent reticulocytosis was found throughout fetal life and for twentyfour hours after birth (suggesting fetal reticulocyte maturation-arrest). Then the reticulocyte curve descended to 25 per cent during the next twenty days. Concomitantly from birth, there was a rise of erythrocytes, indicating peripheral reticulocyte maturation and suggesting "release of inhibition" or postnatal acquisition of a stimulant to complete maturation.

We attempted to "stimulate" (with parenteral liver extract) reticulocyte maturation during late fetal and nursling life, by injecting nine individual fetuses 4 in utero (two operated mothers) and by daily postnatal injections to fourteen nurslings (five litters). No significant change from our normal reticulocyte curve was obtained.

Conclusions: 1. The method offers technical advantages for study of reticulocyte maturation in vivo. 2. Evidence suggesting peripheral reticulocyte maturation is presented. 3. The virtually 100 per cent reticulocytosis of fetal and new-born rats suggests fetal inhibition, or lack, of a factor normally affecting the final stage of reticulocyte maturation. 4. Liver extract failed to stimulate reticulocyte maturation under these conditions.

The Therapeutic Effect of Venesection in Polycythemia. By D. J. Stephens and (by invitation) Nolan KaLTREIDER, Rochester, N. Y.

The effect of venesection has been studied in five patients with polycythemia. Observations of the red

1 Aided by a grant from Mrs. S. duPont Ford.

2 Nicholas, J. S., Anat. Rec., 1925, 31, 385.

${ }^{3}$ Fitz-Hugh, T., Jr., Robson, G. M., and Drabkin, D. L., J. Biol. Chem., 1933, 103, 617.

4 Corey, E. L., Physiol. Zool., 1930, 3, No. 3. 
blood cell count, hemoglobin, hematocrit, reticulocytes, and, in some instances, the blood volume, viscosity and circulation time (arm to tongue) were made before, during and after ten periods of bleeding. The removal of from 1000 to $3000 \mathrm{cc}$. of blood within a few days, by means of repeated phlebotomies of from 200 to $600 \mathrm{cc}$. each, resulted in hematological and clinical remissions varying in duration from a few months to two years. Except for two instances in which a maximum reticulocytosis of 6.3 and 4.3 per cent, respectively, was observed, the reticulocytes remained within the normal range during and after the venesection periods.

The therapeutic effect of venesection compares favorably with that of other measures which have been used in the treatment of polycythemia. Reduction of the blood volume, hematocrit and viscosity by means of venesection has the theoretical advantage of removal from the organism of iron and other potential blood building materials, which are in large part retained and stored by patients in whom the therapeutic effect is produced by means of the hemolytic action of phenylhydrazine.

Further Experiences with Sternal Puncture in the Study of Bone Marrow Changes in Various Hematological Conditions. By G. O. Broun and (by invitation) W. F. Holmes and J. J. Furlong, St. Louis, Mo.

In 1933, Holmes and Broun 1 reported the use of sternal puncture for the clinical investigation of bone marrow. Fifty cases were included in the first reportthis being the first extensive study of marrow specimens obtained by needle puncture under local anesthesia, reported in American literature. Further experience with the method has been secured in the intervening period.

Marrow specimens so obtained are well adapted for study of comparative morphology of marrow cells and peripheral blood cells. It can be shown that contamination with peripheral blood is usually not great. Variations in peripheral blood in general are closely reflected in changes in more immature cell forms in the marrow specimens. Repeated punctures are practicable and offer a means of studying the effects of treatment in hematological disturbances.

In untreated pernicious anemia, the megaloblastic marrow changes are readily demonstrated. A shift to more normal erythrocytic forms occurs under liver therapy.

Therapeutic malaria has been studied during various phases of the disease with definite marrow changes noted.

Characteristic marrow pictures have also been found in hemolytic icterus, acute agranulocytosis, leukemias, aplastic anemia, eosinophilia, lymphocytosis, and acute and chronic infections.

The Excretion of Xylose, Sodium Benzoate, and Urea in Pernicious Anemia in Relation to Maintenance Dosage of Liver Extract. By L. G. Zerfas and (by invitation) O. M. Helmer and P. J. Fouts, Indianapolis, Ind.

As a possible test of absorption twenty-five grams of

1 Holmes, W. F. and G. O. Broun, Proc. Soc. Exper. Biol. and Med., 1933, 30, 1306. xylose (a non-metabolized sugar) was administered to each of forty-seven patients having pernicious anemia. In addition Quick's sodium benzoate liver function test and urea clearances were run on these patients. It was found that, except for several individual exceptions, the xylose excretion and sodium benzoate excretion tended to follow the urea clearance. The urea clearance varied from 23 to 150 per cent of normal. There was a distinctly lower average urea clearance in the patients tested when the red blood cell count was below 4.5 million than in those tested when the red blood cell count was normal. Of the patients examined before and after liver therapy, the four patients known to require liver extract by injection had no increase in urea clearance following liver therapy. All the patients responding satisfactorily to liver extract administered by mouth and who had low urea clearances when in relapse have subsequently shown definite increases in urea clearance. The average urea clearance of the patients requiring liver extract by injection was distinctly lower than that of those responding to oral therapy. No patient having a urea clearance below 50 per cent of normal after maintaining the red blood cell count at normal levels for several months was able to keep the blood at normal levels without injections of liver extract.

On the Fate of Reticulocytes in the Blood Stream. By Raphael IsaAcs, Ann Arbor, Mich.

The blood, during reticulocyte remissions in patients with pernicious anemia, was studied to note the numerical behavior of the reticulocytes and the next older stage, the granule red blood cells. The absence of a proportional increase in granule red blood cells after an increase in the number of reticulocytes, is interpreted as indicating that reticulated red blood cells do not mature in the peripheral circulation, but are removed as such. There is evidence that they are removed by the phagocytic cells in the spleen.

Chlorosis. By Arthur J. Patek, JR. (introduced by Dr. Laurence B. Ellis), Boston, Mass.

Chlorosis is described today as a disease of unknown etiology, which has disappeared mysteriously. Because of the supposed rarity of this disease, four typical severe cases are presented. Since the hypochromic anemia responded readily to the administration of iron, study of causes for iron deficiency in these patients was made.

It is apparent from the analysis that the demand for iron made by growth, loss of iron by menstrual and other blood loss, and insufficient intake of iron are the three important factors in the production of chlorosis. The mothers of two of the four cases had been anemic. It is likely that these patients inherited a meager store of iron at birth.

Conclusions. (1) Chlorosis has not disappeared. (2) Chlorosis is the exaggeration of a normal tendency towards anemia in adolescent girls, created by the increased demand for iron made by growth, by menstrual or other blood loss, and by a diet insufficient in iron-containing foods. 
The Effect of a Deficient Diet on the Blood Picture of the Guinea Pig. By Theodore G. KlumpP and (by invitation) EMIR A. GAw, New Haven, Conn.

With Castle's fundamental experiments as a basis, attempts were made to produce in the guinea pig a deficiency state similar to human pernicious anemia. As an approach to this problem the effect on the blood picture of a diet which might be deficient in the extrinsic factor of Castle was studied. The following diet was employed: Salted soda crackers buttered with a mixture of vitamin free casein, reduced iron, white flour and water; lettuce or cebione; crystalline vitamin $\mathrm{B}_{1}$; $\operatorname{cod}$ liver oil or carotene and viosterol; and cysteine hydrochloride.

Despite a variable weight loss many of the animals lived longer than two months and some indefinitely. When cysteine hydrochloride was withdrawn, alopecia and ulcers of the skin developed. No consistent blood changes were noted. In some of the animals the appearance of prolonged low reticulocyte levels was observed but abrupt increases occurred spontaneously and after injections of liver extracts with equal frequency. Parenteral liver extract failed to influence, in any particular, either the weight or blood picture of the guinea pigs.

The Preservation of Virulent Treponema pallidum and Treponema pertenue in the Frozen State. Вy TномаS B. Turner, New York, N. Y.

Hitherto it has not been possible regularly to maintain the spirochetes of yaws or syphilis in a virulent state outside an animal or human host for longer than a few days. Except in rare instances these organisms lose pathogenicity for laboratory animals when grown on artificial media. When, however, $T$. pallidum and $T$. pertemue are frozen at temperatures approximating $-78^{\circ}$ C. and maintained at this temperature they retain normal morphology and motility, and their virulence for rabbits is essentially unchanged after at least four months.

Infectious material from rabbits was stored in a thermos jug containing dry ice (solid $\mathrm{CO}_{2}$ ) and 95 per cent alcohol. Eight specimens of syphilis virus (Nichols strain) and 6 specimens of yaws virus have been tested before freezing and at intervals of 2 weeks, 1 month, 2 months, and 4 months after freezing. After these intervals the appearance of the organisms was unchanged and upon inoculation of rabbits the incubation period and the character of the initial lesion did not vary significantly from that produced by the same lot of material before freezing. Material from 7 additional strains of yaws spirochetes and lymph node material from 5 different strains of syphilis virus have been tested after 2 months with similar results. With one exception, syphilis spirochetes were not pathogenic for rabbits after desiccation.

Observations on Plasma Fibrinogen Responses. By Thomas Hale Ham (introduced by George $R$. Minot), Boston, Mass.

The blood plasma fibrinogen in 30 normal individuals was found to be within the limits of 180 to $330 \mathrm{mgm}$. per $100 \mathrm{cc}$. of plasma; the usual values ranged from 220 to $270 \mathrm{mgm}$. Repeated fibrinogen determinations were done on one of the normal subjects, and remained remarkably constant over a period of 15 months. In 6 cases of pernicious anemia and one of scurvy, all with severe anemia, the plasma fibrinogen varied from 168 to 272 mgm.

After 5 days of high protein feeding, two normal subjects showed a slight increase in fibrinogen, reaching a maximum after a week, in one subject, and after 12 days in the other. An average fibrinogen level of 180 mgm. was observed in a pernicious anemia patient, following a prolonged low protein diet; when fed a diet rich in liver, over a period of 10 weeks, the fibrinogen increased gradually to an average level of $270 \mathrm{mgm}$.

Fibrinogen responses were studied in: (1) infectious, degenerative and neoplastic diseases; (2) following the intravenous injection of typhoid vaccine; and (3) in hyperthermia induced by high environmental temperature. The elevation of plasma fibrinogen was found to be one of the most frequent, non-specific responses of the body to noxious stimuli; it was similar in nature to the temperature and white blood cell responses, but was independent from them. Two to three days after the injection of a single, large dose of typhoid vaccine in normal subjects, the fibrinogen rose to a maximum, and required from 6 to 10 days to return to its previous value. Artificially induced hyperthermia produced only a slight, temporary fibrinogen rise. Prolonged elevation of the fibrinogen was associated with chronic infection and, in 2 cases, with neoplasm.

The fibrinogen failed to rise in 3 cases of overwhelming infection; autopsy revealed severe liver damage in 2 of these cases, but only slight damage in one. Fibrinogen failed to rise in one case of toxic hepatitis, showing severe liver necrosis at postmortem.

The Advantage to the Diabetic of Protein as a Source of Glucose. By JEROME W. CoNN (by invitation) and L. H. Newburgh, Ann Arbor, Mich.

The capacity of a diabetic to dispose of glucose is measured in terms of the calculated total glucose released from his diet in 24 hours. Little consideration has been given to the rate at which this release occurs. These experiments show that rate is as important a factor as total yield.

Blood sugar curves following ingestion of glucose were compared with those following ingestion of enough protein to yield equivalent amounts of glucose. Normals and diabetics were studied. Blood urea nitrogen determinations were used to indicate rate of metabolism of protein.

The slowly rising blood urea nitrogen after ingestion of protein indicates the slow rate of deamination of amino acids in the liver. The glucose derived in this process is thus made available at a relatively slow rate. The inability of a diabetic to dispose of large quantities of glucose is partially compensated if the glucose is pre- 
sented for utilization slowly and evenly. In thirteen diabetics studied the average maximum increase in blood sugar after ingestion of carbohydrates was $160 \mathrm{mgm}$. per $100 \mathrm{cc}$. and was invariably attended with significant glycosuria. When an equivalent amount of glucose was derived from protein the average maximum increase was $37 \mathrm{mgm}$. per $100 \mathrm{cc}$. and produced no glycosuria.

Experimental Production of Macrocytic Anemia in Pregnancy. By Katharine O'Shea Elsom (introduced by T. Grier Miller), Philadelphia, $\mathrm{Pa}$.

A macrocytic anemia was produced in eight pregnant women who, from the fourth month until delivery, were given an experimental diet deficient in the vitamin $B$ complex. The diet was calculated to contain approximately one-half of the theoretical vitamin $B$ requirement, to be adequate in all other vitamins, in calories and in protein. Additional iron was given as ferrous sulphate, and vitamins $\mathrm{A}$ and $\mathrm{D}$, as haliver oil and viosterol. Control patients who received a completely adequate diet plus the supplements mentioned, did not develop anemia. The anemia was characterized by a slight fall in red cells and hemoglobin, slight increase in color index, marked increase in mean corpuscular volume, reticulocytosis, macrocytosis and the appearance of poikilocytes, polychromatic cells and immature white cells in the stained blood. The anemia responded to brewer's yeast and to Liver Extract No. 343 intramuscularly.

Gastric acid was variable in the anemic patients. Tongue changes were also variable, some patients showing no change, others showing marked glossitis. All complained of gastro-intestinal distress. Numbness and paresthesias of the lower extremities occurred in all the patients on the deficient diet and in some was accompanied by temporary loss of vibratory sense. These symptoms and physical signs, not present in the control patients, disappeared promptly after administration of brewer's yeast or liver extract.

The Use of Ferrous Gluconate in Hypochromic Anemia. By Paul ReznikofF and (by invitation) WALter F. Goebel, New York, N. Y.

To obtain a ferrous compound which is soluble and does not coagulate proteins in vitro or cause necrosis when injected, ferrous gluconate was made. Ferrous gluconate prepared aerobically was given by mouth or by injection to 16 milk-fed rats derived from milk-fed mothers, so that they received $1 \mathrm{mgm}$. of iron daily. Seven control animals were also studied. Reticulocytes rose promptly to a peak within five days. A fairly high hemoglobin level occurred in the animals receiving the gluconate orally in three weeks; in the injected animals in two weeks.

Eight patients suffering from hypochromic anemia have been treated with ferrous gluconate to date, three by injection and five by oral administration. Prompt reticulocyte rises and adequate hemoglobin responses have ensued. No unpleasant systemic effects were seen and practically no local reactions to the injections occurred even when a quantity containing $25 \mathrm{mgm}$. of iron was given daily.

Ferrous gluconate is best prepared by adding one equivalent of ferrous sulfate to an aqueous solution of barium gluconate in an atmosphere of nitrogen and then concentrating and filtering the crystalline derivative from the mother liquor.

The Rôle of Lipids in Immune Reactions. By Frank L. Horsfall, JR., and K. GoOdNER (introduced by Thomas M. Rivers), New York, N. Y.

Specific agglutination and precipitation cannot be obtained with horse and rabbit antipneumococcus sera from which the lipids have been removed. This extraction, however, does not affect the capacity of the antibody to unite with the specific antigen. The full reactive properties of antipneumococcus horse serum return upon the addition of small amounts of lecithin. For antipneumococcus rabbit serum cephalin is required for restoration.

These phosphatides, which appear to be essential for the in vitro demonstration of immune reactions, must be carefully distinguished from the large amount of heterologous and non-essential lipid found in immune aggregates. The latter, for example, may constitute from 5 to 80 per cent of an immune precipitate, and appears, for the most part, to have been non-specifically absorbed. The single exception to this lack of specificity is that with immune rabbit serum, lecithin is selectively absorbed, whereas horse serum immune aggregates fix cephalin. Thus the non-essential phosphatides occupy a position paradoxical to those of the essential.

It seems not unlikely that, in addition to the important rôle of lipids in the in vitro demonstration of immune reactions, they exert a profound influence in the capacity of an animal to utilize antibodies.

Multiple Cases of Pneumococcic Infections in Families with the Demonstration of the Development of Antibodies in Contact Carriers. By R. CARMICHAEL Tilghman (by invitation) and Maxwell Finland, Boston, Mass.

The evidence obtained from a study of multiple cases of pneumococcic infections in contact groups indicated that they resulted from exposure to an antecedent case. With the exception of two instances, all the pneumococcic infections were observed in families. Twentythree groups included fifty-four individuals ill of pneumococcic infections of homologous types. The majority of the contact infections occurred in less than fourteen days after exposure, and the clinical manifestations within the groups suggested a similar severity.

Detailed bacteriologic studies made on the entire family and contacts of five of the groups demonstrated a high incidence of carriers of the pneumococcus responsible for the infection in the relatives. Immunologic data obtained from a study of the blood of the carriers and non-carriers of the disease-producing pneumococci showed that specific antibodies may develop in those individuals who are carriers but who do not become ill with the in- 
fection. One instance was encountered in which an individual, who did not possess antibodies against pneumococcus Type $\mathrm{V}$, developed specific agglutinins and mouse protective antibodies after he became a carrier of the Type $\mathrm{V}$ pneumococcus without any evidence of infection. In another instance, pneumococcus Type XXII agglutinins in low titer appeared during convalescence from Type V pneumonia, and later the Type XXII was cultured from the patient's throat.

The Excretion of Electrolytes in the Absence of the Colonic Absorption of Intestinal Fluids. By STUART WeLCH (by invitation) and E. G. WAKEFIELD, Rochester, Minn.

We have observed the extent of loss of fluids and electrolytes among patients who had been subjected to ileostomy and those who had disease characterized by a chronic diarrheal state. Among those who had an ileac stoma, the excretion of base through the loss of intestinal fluid was apparent as 90 per cent of the sodium was excreted in the ileac dejecta. However, there was a compensatory decrease of the sodium in the urine to 10 per cent of the total amount of sodium excreted, whereas the excretion of chloride in the ileac dejecta was 30 per cent of the total chloride excreted.

In chronic diarrheal states, an increased loss of fluids and electrolytes in the feces similarly produces a decrease in the amount of fixed base in the urine. The excretion of chloride in the feces, as in the cases in which the patients have been subjected to ileostomy, amounts to 30 to 60 per cent of the total excretion of chloride.

Excessive loss of ileac excreta may produce clinical symptoms comparable in some ways to those observed in states of suprarenal insufficiency; and just as in suprarenal insufficiency, these symptoms also may be relieved by replacing fluid and electrolytes.

The Heart Fifteen to Twenty Years after Severe Diphtheria. A Follow-Up Study of 100 Cases. By WILliam Paul Thompson and Sherman E. Golden (by invitation), and PAUL D. White, Boston, Mass.

In 1926, one hundred individuals were examined five to ten years after severe diphtheria. No evidence of heart disease was found, although a recent review of the electrocardiograms taken then has revealed four cases with a duration of the Q.R.S. complexes of 0.11 second and prominent $S$ waves in Lead II, previously considered normal but today open to some question. These four cases may or may not have had these rather wide Q.R.S. waves before their diphtheria; we have encountered similar complexes in the routine examination of occasional individuals with normal hearts.

Eighty-three of the original one hundred cases have now been re-examined, and two more are known to be dead, one of rheumatic heart disease and one of pneumonia. Two of the eighty-three cases followed up now have arterial hypertension but normal sized hearts and two have rheumatic heart disease. Electrocardiograms in the eighty-three cases are essentially unchanged after the additional years. The four with questionably abnormal Q.R.S. complexes now have almost identical electrocardiograms. There is no case with an abnormally long $\mathrm{P}-\mathrm{R}$ interval, although in three this interval measures 0.20 second (the same as ten years ago in one case, while the other two have increased to this length from the 0.15 and 0.16 seconds they showed before).

An additional seventeen cases have been examined, so that the present series actually examined numbers one hundred. These likewise had severe diphtheria fifteen to twenty years ago. One has a mild hypertension and another rheumatic heart disease, but electrocardiographic abnormalities were not found.

This follow-up series of cases has revealed then, 15 to 20 years after severe diphtheria, no evidence of heart disease that can be definitely attributed to the diphtheria.

The Chloride Content of the Cerebrospinal Fluid in Various Diseases and Its Relationship to the Chloride Content of the Serum. By $\mathrm{H}$. Houston MerRitT and Frank Fremont-Smith, Boston, Mass.

The chloride content of the cerebrospinal fluid of 2,953 patients with various diseases has been determined. In 268 of these patients simultaneous determinations of the chloride content of the serum were made. The results can be summarized as follows:

1. The chloride content of the cerebrospinal fluid is normal or very near to the normal limits in patients with diseases not accompanied by fever, vomiting or evidences of an inflammatory reaction in the nervous system.

2. The chloride content of the cerebrospinal fluid is reduced in patients with diseases accompanied by fever, vomiting or evidences of an inflammatory reaction in the nervous system. Very low values may be found occasionally in patients with any of these diseases, but they are most frequent in patients with meningitis.

3. The chloride content of the cerebrospinal fluid may be reduced, or it may be greatly increased in patients with uremia.

4. The normal ratio of the chloride content of the cerebrospinal fluid to that of the serum is as 1.2 is to 1 . This ratio is also usually found in patients with an abnormal chloride content in the cerebrospinal fluid.

The amount of chlorides in the cerebrospinal fluid is dependent upon the concentration of the chlorides in the serum. Changes in the chloride content of the cerebrospinal fluid are chiefly a reflection of changes in the serum. Other factors such as the protein content and acidity of the fluid play only a minor rôle.

Vitamin $C$ and Infection. By JAMES M. FAULKNER and (by invitation) F. H. L. TAYLOR, Boston, Mass.

Titration of reduced cevitamic acid in blood serum and plasma with 2.6 dichlorphenolindophenol solution has been utilized in the study of the effect of infection on the vitamin $\mathrm{C}$ metabolism. The method used employs certain modifications of previously described techniques which, it is believed, increase its accuracy.

With this technique estimations of the level of cevi- 
tamic acid in the blood of 33 normal individuals varied from 0.83 to $2.43 \mathrm{mgm}$. per $100 \mathrm{cc}$. In 13 adult patients with clinical scurvy the values ranged from 0.24 to 0.63 with an average value of 0.47 . In a study of 50 patients with various infectious diseases who were previously known to have been on adequate diets as regards vitamin $\mathrm{C}$, it was found that the blood levels of cevitamic acid were frequently reduced to levels seen in scurvy. In such patients the urinary output of vitamin $C$ was low and did not rise after the oral administration of a single large dose (1 gram) of the pure substance although the blood level regularly showed a slight rise lasting over several hours. The same response has been noted in patients with scurvy without infection. In the presence of chronic active infection, such as advanced pulmonary tuberculosis, large daily doses of vitamin $C$ (between 300 and 500 $\mathrm{mgm}$.) were required to bring the blood value up to the normal level and to maintain it there.

The findings are confirmatory of previous observations by others and ourselves that the requirements of the body for vitamin $\mathrm{C}$ during infection may be greatly increased.

\section{A Peptide of Thyroxine with Greater Calorigenic Activ-} ity Than Desiccated Thyroid: A Consideration of Methods of Assay. By W. O. Thомpson and (by invitation) S. B. NAdLER, P. K. Thompson, S. G. TAYLOR, III, and L. F. N. DiCkIE, Chicago, Ill.

In 14 of 17 patients with myxedema the oral administration of a peptide of thyroxine produced about 30 per cent more calorigenic activity per milligram of iodine than desiccated hog thyroid. In 12 of 16 patients it was about one-third more active than thyroxine when both were given by the subcutaneous route.

Since the accuracy of deductions depends upon the accuracy of methods of assay, a large series of observations was carried out to determine the best method in man, with the following results:

(1) A given amount of thyroid produced about onethird more activity when administered in divided doses over a period of 13 days than when given in a single large dose. However, the increased activity of the peptide was evident by both methods. Data now being collected by a third method (maintenance dose) also suggest that the effect of the peptide is greater.

(2) Erroneous conclusions may be drawn if:

(a) The amount and duration of the increase in metabolism are not observed as well as the rate at which the increase occurs.

(b) The doses compared do not contain the same amount of iodine and the comparison is not made in the same patient.

These findings have an important bearing on the hypothesis that the activity of thyroxine is enhanced by its natural combination and that the activity of desiccated thyroid is not proportional to its total iodine content.

Acoustical Properties of Stethoscopes of Various Types. By Franklin D. Johnston, Ann Arbor, Mich.

To obtain information regarding the sound transmis- sion properties of commonly used stethoscopes, a number of end-pieces both of the bell and Bowles type have been tested. These studies were made while the various units were actually transmitting sounds derived from the body, or under conditions acoustically similar. The results indicate that most of the bell type end-pieces tested behave in a similar manner for both low and high pitched sounds. The selectivity for high pitched sounds displayed by the Bowles type unit was found to be due entirely to the presence of the diaphragm, since its removal destroyed this property.

Using fundamental acoustic principles concerning the transmission of sound energy from a dense into a rare medium it can be shown that an important function of a stethoscope is to increase materially the very small per cent of energy usually transmitted across the chest wall. The application of these ideas to stethoscope end-piece design is discussed. Studies relating to air conduction through tubes of different types are now in progress.

The Effects of Mecholine on the Frog's Heart. By A. E. СоHN and A. G. Macleod, New York, N. Y.

The influence of pharmacological agents and pathological changes upon the fundamental properties of heart muscle still requires study. In examining the effects of such agents as mecholine and the pure glucosides of the strophanthin group certain important phenomena were observed. In this communication the effects of mecholine only will be described. The drug was given intravenously to large frogs and action currents recorded with cephelad-caudad and direct leads from the surface of the heart. The duration of the secondary deflection of both auricle and ventricle was greatly shortened; the portion of the curve which corresponds to the R-T segment of the electrocardiogram was consequently short. Pari passu the refractory period shortened. Presumably because of the last mentioned effect ectopic rhythms often developed simulating fibrillation and flutter. The phenomena were transient and complete recovery occurred within a short time. All the effects of the drug were abolished by atropine. Atropine by itself produced no detectable effect. The relation of these phenomena to the intrinsic and extrinsic nervous mechanisms of the heart is still being investigated.

Studies of the Circulation in Spontaneous Myxedema. By Harold J. Stewart and (by invitation) JoHN E. Deitrick and Norman F. CRane, New York, N. Y.

This paper presents a summary of the data obtained in a study of the circulatory functions of the four patients suffering from typical spontaneous myxedema. Numerous observers have studied individual functions of the heart and circulation in myxedema, but we have attempted to gain as complete a picture of the circulation as possible by the use of various methods applied to the same individual. We have measured the cardiac output (acetylene method, 3 samples of gas being taken), arm to tongue circulation time (decholin), venous pressure (direct method), cardiac size (2 meter $x$-rays), 
cardiac work, basal metabolism, vital capacity and blood pressure in these patients during the myxedematous state and after the basal metabolic rate has approached normal as a consequence of giving thyroid extract. Electrocardiograms were also taken. All observations were made with patients in a basal metabolic state.

During the myxedematous state when the basal metabolic rate was low, the cardiac output was diminished, the circulation time prolonged, the heart usually large. With the administration of thyroid extract and the return of the basal metabolic rate toward normal, the cardiac output increased, the circulation time became shorter and the heart became smaller. There was no marked change in heart rate, blood pressure or venous pressure. In these patients, a correlation was observed between cardiac output and circulation time, in that the greater the cardiac output, the shorter the circulation time. It was demonstrated again the correlation which Blumgart and others have shown in myxedema, namely that as oxygen consumption becomes greater the circulation time becomes shorter. It was also shown that as oxygen consumption becomes less the arteriovenous oxygen difference becomes greater. During the myxedematous state the work performed by the left ventricle may not be commensurate with the size of the heart, but with the administration of thyroid extract and the increase in oxygen consumption, the work of the heart becomes commensurate with its size.

The Immediate Response of the Serum Cholesterol to the Ingestion of Citrus Fruit Juices. By Fred FrTz (by invitation) and Herman O. Mosenthal, New York, N. Y.

In a previous paper from this laboratory it was noted that the ingestion of orange juice during profound hypoglycemia (insulin induced) was followed by a marked fall of the plasma cholesterol. This report describes further studies on this problem.

The cholesterol partition of the serum (method of Schoenheimer and Sperry) was studied in humans before and at half hour intervals for two hours after the ingestion of $300 \mathrm{cc}$. of orange juice. Similar studies were made with $200 \mathrm{cc}$. of unsweetened lemon juice, 10 grams of citric acid and crystalline vitamin $C$ (ascorbic acid), the latter given intravenously. Orange juice effected a conspicuous drop in the ester cholesterol fraction in nine of thirteen cases studied. Analogous results were obtained in five of eight cases with lemon juice. The response to citric acid was not uniform; ascorbic acid produced no significant changes. Dilution of the blood, as measured by the corpuscle volume per cent, did not account for the variations observed in the serum cholesterol.

It is concluded that the ingestion of orange and lemon juice produces a marked diminution in the ester cholesterol of the serum and that the citric acid and ascorbic acid content of these juices do not account for the changes observed.
Factors Influencing the Concentration of Pituitary Gonadotropic Hormones from Urine by the Alcohol Precipitation Method of Zondek. By Hirsh W. Sulkowitch (by invitation) and Fuller Albright, Boston, Mass.

The determination of pituitary (as opposed to placental) gonadotropic substances in the urine has become an important clinical test to differentiate between hypogonadism of pituitary and ovarian origin and to follow the effect of treatment in patients with overproduction of this hormone. The method most used is the alcohol precipitation method of Zondek. This when carried out according to the original procedure or its modifications leads to inconstant results. The present study was undertaken to determine what precautions or modifications were necessary to perfect the procedure. It was found that if the $\mathrm{pH}$ of the alcohol and urine mixture was increased from five to nine there was a steady increase in the amount of gonadotropic hormone recovered. The optimal $\mathrm{pH}$ for precipitation was between eight and nine. By carrying out the procedure at the optimal $\mathrm{pH}$ it was found that very constant results were obtained from any one patient and absolutely reproducible results from any one specimen of urine could be obtained.

The study includes quantitative data on the efficiency of the final procedure adopted and a discussion of differences between the pituitary and placental gonadotropic hormones in respect to their precipitation by alcohol.

Studies in Pernicious Anemia: Surgical Elimination of Gastro-intestinal Factors. By Lours Goodman, Arthur Geiger, and Louie N. Claiborn (introduced by John P. Peters), New Haven, Conn.

Experiments designed to elucidate the nature and rôle of Castle's "intrinsic factor" in the pathological physiology of pernicious anemia were undertaken on young swine. The main sources of this factor were directly attacked by four types of operation, namely: total gastrectomy to eliminate the chief source, isolation of the stomach to exclude gastric digestion but retaining possible internal secretions, duodenectomy to evaluate the rôle of the duodenum recently emphasized by Meulengracht, and finally total gastrectomy plus duodenectomy. The differentiation between a hormonal and enzymatic principle is further being sought by the clinical assay of the livers of new-born pigs obtained from agastric sows.

The animals were fed an adequate diet supplemented by iron and lacking only the preformed sources of the antianemic principle. Contrary to the observations of Ivy and of Bence, growth and development proceeded normally in all pigs except those subjected to duodenectomy, and in the single "gastric pouch" animal. No significant anemia resulted, even during the course of repeated pregnancies in sows agastric for one to two years. Bone marrow and spinal cord studies were also made. Human assay of the livers of gastrectomized swine revealed a striking loss of reticulocytogenic power six months after total gastrectomy, with a significant loss evident as early as the second month. 